\title{
ANÁLISE DE ESTACIONARIEDADE DE SÉRIES HIDROLÓGICAS NA BACIA INCREMENTAL DE ITAIPU
}

\author{
Ingrid Illich Müller, Cláudio Marchand Krüger e Eloy Kaviski \\ Centro de Hidráulica e Hidrologia Prof. Parigot de Souza - CEHPAR \\ Caixa Postal 1309 - CEP 80001-970 Curitiba, PR
}

\section{RESUMO}

O aumento das vazões médias afluentes à usina hidrelétrica de Itaipu após a década de 1970 apresenta uma intensidade considerável e vem ocorrendo ao longo de um período de tempo significativo. Neste artigo é apresentada uma síntese dos estudos desenvolvidos para a bacia do rio Paraná, com ênfase na região mais próxima da usina de Itaipu. Os objetivos principais são os seguintes: (i) análise da estacionariedade de séries de vazões e precipitações das bacias hidrográficas dos rios afluentes à usina de Itaipu; (ii) estimativa da percentagem de variação ocorrida nas vazões e precipitações médias após 1970. As análises foram realizadas com base em diferentes técnicas estatísticas aplicadas às séries históricas disponíveis na bacia do rio Paraná em Itaipu. Análises adicionais foram realizadas, em nível preliminar, envolvendo estimativas da evapotranspiração real e aspectos meteorológicos e de uso do solo. Os estudos desenvolvidos permitem concluir que houve aumentos significativos de vazões e precipitações médias após 1970. Aparentemente, o fenômeno do aumento de vazão decorre dos efeitos conjuntos do aumento da precipitação (que pode ser transitório), diminuição da evapotranspiração provocada pela retirada da mata nativa e aumento da infiltração da chuva, facilitada pelo adequado manejo do solo. Os aumentos de precipitação podem justificar o aumento de vazões nas regiões situadas a montante na área de estudo. Para as bacias situadas mais a jusante, o aumento de vazão é incompatível com o aumento de precipitação, indicando que outros fatores, como a mudança de uso do solo, interferem no processo.

\section{INTRODUÇÃO}

Este artigo apresenta uma síntese dos estudos desenvolvidos de análise das séries temporais de vazão e precipitação das principais bacias do rio Paraná contribuintes à usina hidrelétrica de Itaipu.
Estudos realizados anteriormente (Itaipu Binacional, 1995) concluíram, em síntese, que o aumento de vazões afluentes a Itaipu é permanente e que o aumento é devido ao processo de desmatamento ocorrido neste século em grande parte da bacia. Testes estatísticos aplicados sobre séries de precipitações disponíveis na área do estudo indicaram que não houve aumento significativo na precipitação. Conforme suas próprias recomendações, estes estudos necessitavam de uma reavaliação quanto aos métodos utilizados e quanto ao grau de confiança dos resultados obtidos. O Instituto de Pesquisas Hidráulicas - IPH (Tucci e Clarke, 1996a, 1996b) realizou uma avaliação dos estudos anteriores e apresentou recomendações iniciais sobre os estudos complementares a serem realizados. Nos relatórios apresentados pelo IPH consta uma revisão da literatura sobre os processos físicos envolvidos no fenômeno do aumento de vazões na bacia. As principais conclusões apresentadas são as seguintes: (i) o desmatamento de florestas naturais produz aumento da vazão média na bacia hidrográfica e este processo ocorreu de forma importante na bacia afluente a Itaipu; (ii) a precipitação média após 1970 é 6\% superior à precipitação média do período anterior (1932-1970), mas as análises estatísticas anteriormente realizadas indicaram que este aumento não é significativo. Entre os estudos de curto prazo recomendados pelo IPH encontram-se estudos estatísticos visando a análise de tendência das séries de precipitações e vazões.

Os objetivos principais do presente artigo são os seguintes: (i) análise da estacionariedade de séries de vazões e precipitações coletadas em pontos de observação representativos das bacias hidrográficas dos rios afluentes à usina hidrelétrica de Itaipu; (ii) estimativa da percentagem de variação ocorrida nas vazões e precipitações médias após 1970. As análises foram realizadas através de diferentes técnicas estatísticas aplicadas às séries históricas disponíveis, sem levar em consideração dados fisiográficos das bacias envolvidas, como dados de desmatamento, ocupação do solo e tipos de 
solos. Para a abordagem do problema, foram aplicadas várias técnicas sugeridas nas avaliações realizadas pelo IPH (Tucci e Clarke, 1996b).

O estudo foi dividido em duas etapas: na primeira, foram realizadas análises de estacionariedade das séries de vazões e precipitações dos postos localizados na área incremental a jusante da foz do rio Paranapanema e também nas sub-bacias afluentes da margem esquerda do rio Paranapanema (Itararé, Cinzas, Tibagi e Pirapó). Nesta primeira etapa, foram aplicados diversos testes estatísticos às séries de vazões e precipitações médias anuais de estações fluviométricas e pluviométricas localizadas, em sua maioria, no Estado do Paraná. Para os postos fluviométricos que apresentaram correlações seriais significativas nas vazões médias anuais, foram realizadas análises de estacionariedade através de simulações Monte Carlo. Com o intuito de avaliar a estacionariedade das características da precipitação diária, foram realizadas análises da freqüência e intensidade da precipitação média diária, utilizando cadeias de Markov para a freqüência e distribuições Gama para a modelagem da intensidade da precipitação.

Em uma segunda etapa do estudo foram realizadas as seguintes análises: (i) análise de estacionariedade das séries de vazões médias anuais naturais de 32 usinas hidrelétricas da bacia do rio Paraná. As séries utilizadas são provenientes do banco de dados de vazões naturais utilizado pelo Setor Elétrico; (ii) análise de estacionariedade de séries fluviométricas de postos localizados nas bacias dos rios Paranaíba, Grande, Tietê e Paranapanema; (iii) análise de estacionariedade de séries pluviométricas de postos localizados no Estado de São Paulo; (iv) quantificação da variação da vazão média anual e precipitação média anual após 1970.

Com o intuito de apoiar as conclusões obtidas a partir das análises estatísticas, foram realizadas análises complementares envolvendo aspectos da inter-relação entre a precipitação e a vazão, buscando o estabelecimento de bases para a investigação das causas dos fenômenos detectados. Estas análises adicionais abrangem estimativas da evapotranspiração real para alguns locais selecionados, nos Estados do Paraná e São Paulo, e estudos preliminares relacionados com os aspectos meteorológicos e de uso do solo que pudessem explicar a ocorrência do fenômeno de aumento de vazões e precipitações.

\section{ESTUDOS DESENVOLVIDOS}

\section{Análise dos dados básicos}

Para a primeira etapa do estudo, foram coletados os dados de 135 estações pluviométricas e 40 estações fluviométricas. Foram analisados da- dos de chuvas diárias, cotas diárias, vazões diárias, medições de descarga e curvas de descarga. Para a segunda etapa do estudo, foram coletados os dados de vazões médias mensais de 19 estações fluviométricas localizadas nas bacias dos rios Paranaíba, Grande, Tietê e Paranapanema, dados de vazões médias mensais naturais do período 1931-94 de 32 usinas e dados de precipitações médias mensais de 61 estações pluviométricas do Estado de São Paulo. O número total de estações envolvidas no estudo, entre estações principais e auxiliares, perfaz um total de, aproximadamente, 200 estações pluviométricas e 100 estações fluviométricas.

$\mathrm{Na}$ primeira etapa do estudo foram revisadas as curvas de descarga de todos os postos fluviométricos, sendo redefinidas aquelas que apresentavam problemas ou alterações provocadas pela inclusão de medições de descarga mais recentes. As curvas de descarga dos postos fluviométricos localizados nas bacias dos rios $\mathrm{Pa}$ ranaíba, Grande, Tietê e Paranapanema não foram analisadas, pois os dados destas bacias foram coletados ao final do estudo, na forma de vazões médias mensais. Para cada estação pluviométrica e fluviométrica foram realizados preenchimentos de falhas a nível mensal. Foram consistidos os dados de 61 estações fluviométricas e 101 estações pluviométricas.

\section{Análise da estacionariedade das séries de vazões e precipitações}

Testes estatísticos - Os estudos desenvolvidos visando a análise de estacionariedade das séries de vazões e precipitações foram essencialmente baseados em análises estatísticas. Foram aplicados testes estatísticos paramétricos e nãoparamétricos às séries de vazões médias anuais de postos localizados na área incremental (neste trabalho, a área incremental engloba as sub-bacias do rio Paraná situadas a jusante da foz do rio $\mathrm{Pa}$ ranapanema e também as sub-bacias dos afluentes da margem esquerda do rio Paranapanema: Itararé, Cinzas, Tibagi, e Pirapó), e também nas bacias dos rios Paranaíba, Grande, Tietê e Paranapanema. Adicionalmente, foram aplicados os mesmos testes às séries de vazões naturais de 32 usinas localizadas na bacia do rio Paraná a montante de Itaipu. Para os dados pluviométricos, foram aplicados os testes estatísticos aos dados de precipitação média anual de postos localizados na bacia do rio Paraná a montante de Itaipu, dentro dos Estados do Paraná e São Paulo. 
Os testes aplicados foram: Wald-Wolfowitz, Cox-Stuart, Coeficiente de Correlação de Spearman, Mann-Kendall, Wilcoxon, Kruskal-Wallis, $t$ de Student e de Tendência Polinomial. Em todos os testes aplicados, é testada a hipótese nula de que a série é homogênea, ou seja, que não há tendência, contra a hipótese alternativa de existência de tendência.

Os testes que foram usados podem ser agrupados em três grupos: (i) os testes Wilcoxon, KruskalWallis e $t$ de Student, que trabalham com subamostras extraídas da série total; (ii) os testes de Wald-Wolfowitz, Cox-Stuart, Coeficiente de Correlação de Spearman e Mann-Kendall, que obtém as estatísticas correspondentes dos testes trabalhando com toda a série e; (iii) os testes de Tendência Polinomial.

Do primeiro grupo de testes, o teste paramétrico $t$ de Student (Spiegel, 1978) é o mais simples e testa a igualdade das médias de duas sub-amostras. Os testes não-paramétricos de Wilcoxon (Snedecor e Cochran, 1967; Loucks, Stedinger e Haith, 1981) e Kruskal-Wallis (Siegel, 1956) trabalham com subamostras ordenadas da série total e verificam a posição relativa dos elementos das sub-amostras antes e depois da ordenação, para na seqüência aplicar a estatística do teste correspondente.

Os testes do segundo grupo, Wald-Wolfowitz (Morettin e Toloi, 1981), Cox-Stuart (Siegel, 1956), Spearman (Siegel, 1956; Morettin e Toloi, 1981) e Mann-Kendall (Eletrobrás, 1987) verificam, segundo a estatística de cada teste, se a série apresenta ou não valores em uma mesma direção, indicando a existência de tendência. Por exemplo, o teste de Spearman calcula o somatório dos quadrados das diferenças entre a posição que cada valor ocupa na série e a posição que este mesmo valor ocupa na série ordenada. A estatística do teste indica que para valores pequenos deste somatório, a série está quase ordenada, portanto, para aquele nível de significância, a série apresenta tendência.

A análise de tendência polinomial (Hoel, 1984; Johnston, 1984) para estimar a tendência consiste em se ajustar aos valores observados da série temporal (vazão anual e precipitação total anual) modelos lineares e exponenciais. Neste estudo os parâmetros dos modelos foram estimados pelo método dos mínimos quadrados generalizado e considerada a hipótese de que os ruídos são correlacionados.

Cada um dos testes analisa a série temporal de observações de forma diferenciada, o que pode conduzir a diferenças nos resultados obtidos para cada um dos testes para um mesmo nível de significância.

Simulações Monte Carlo - No caso de séries autocorrelacionadas, a princípio não poderiam ser aplicados os testes estatísticos, pois estes em geral assumem como requisito básico de aplicabilidade a independência serial da variável analisada. Neste caso, uma das formas de realizar a análise de estacionariedade é o uso de simulação Monte Carlo, gerando-se séries sintéticas autocorrelacionadas através de um modelo estocástico, preservando-se algumas propriedades estatísticas da série original. A maior dificuldade e também o ponto crítico desta abordagem é determinar a forma teórica do modelo estocástico mais apropriado à série amostral. A identificação do melhor modelo é realizada através de um processo iterativo, analisando-se ao final do ajuste de um determinado modelo, as propriedades dos resíduos do modelo, principalmente em termos da independência serial e normalidade dos mesmos. A identificação do modelo se baseia principalmente no comportamento das funções de autocorrelação e autocorrelação parcial da série temporal observada. Resumidamente, a seqüência de passos seguida na análise de estacionariedade utilizando simulação Monte Carlo foi a seguinte:

1. identificação do modelo estocástico mais adequado à série de vazões médias anuais. Inicialmente, os modelos a serem considerados são gerais, do tipo $\operatorname{ARIMA}(p$, $d, q)$, onde $p, d$ e $q$ deverão estar geralmente entre 0 e 2 ;

2. as séries de vazões médias anuais são transformadas em variáveis adimensionais $z_{t}$, obtidas através de $z_{t}=\left(Q_{t}-\bar{Q}_{k}\right) / S_{k}$, onde $Q_{t}$ é a vazão média anual no ano $t$, $\bar{Q}_{k}$ é a vazão média do período $k$. A série histórica é dividida em dois períodos, antes e depois do ano de início da eventual mudança de tendência. $S_{k}$ é o desvio-padrão das vazões médias anuais do período $k$. A modelagem da série temporal é realizada sobre as variáveis adimensionais $z_{t} . \mathrm{Na}$ geração das séries, cada variável $z_{t}$ gerada é transformada em vazão através de $Q_{t}=z_{t} S_{k}+\bar{Q}_{k}$. Este procedimento é semelhante ao usado no tratamento de vazões médias mensais em locais com sazonalidade;

3. ajuste do modelo estocástico;

4. obtenção da distribuição de freqüência dos parâmetros de interesse.

Através da geração de um número suficientemente grande de séries sintéticas, a distribuição de probabilidades do parâmetro de 
interesse (no caso, a diferença de médias e razão de variâncias entre dois sub-períodos da amostra) pode ser determinada via freqüência relativa a partir dos valores obtidos ao longo das simulações.

\section{Análises da freqüência e intensidade}

da chuva diária - Com o objetivo de auxiliar nas análises de estacionariedade das séries anuais de precipitações, foram analisadas as séries diárias de precipitações de alguns postos do Estado do Paraná, com vistas a detectar possíveis alterações na freqüência e intensidade dos eventos pluviais diários.

Pesquisas no assunto de modelagem de precipitações diárias (Clarke, 1994) têm proposto a aplicação de modelos de cadeia Markoviana para o estudo da freqüência e distribuições Gama para a intensidade das precipitações médias diárias. Esta abordagem foi utilizada para a modelagem dos dados de chuva, com o objetivo de comparar a forma dos modelos matemáticos ajustados aos dados de precipitações médias diárias de dois subperíodos da amostra, de forma a detectar eventuais alterações no comportamento da freqüência e intensidade dos eventos pluviais. No caso da freqüência, esta abordagem consiste em ajustar funções às freqüências observadas na série histórica, das seqüências de dias secos e úmidos. No caso do presente estudo, os modelos matemáticos ajustados consideram cadeias de Markov de primeira ordem, em que um estado (seco ou úmido) em um dia só depende do estado no dia anterior. Para a intensidade, uma variável é definida como o excesso de chuva acima de um valor mínimo $(0,1 \mathrm{~mm}$, no caso). A distribuição da intensidade da chuva diária é geralmente bastante assimétrica, recomendando-se o uso de distribuições Gama. A análise de estacionariedade da freqüência e intensidade da precipitação média diária foi baseada na comparação das funções ajustadas aos períodos anteriores e posteriores a 1970. Expressões teóricas foram ajustadas separadamente para cada sub-período, e a seguir foram comparadas para verificação estatística da probabilidade de existir uma alteração nos parâmetros obtidos para cada sub-período.

\section{Estimativa da percentagem de variação das vazões e precipitações após 1970}

\author{
Estimativa da variação das vazões \\ médias anuais após 1970 - A partir das
}

séries de vazões médias anuais disponíveis na área de estudo foi estabelecido um critério para a estimativa de uma série de vazões médias anuais específicas (vazão dividida pela área de drenagem) válida para uma determinada área ou bacia. As áreas analisadas foram divididas da seguinte forma: (i) área incremental abrangendo apenas os afluentes da margem esquerda do rio Paranapanema (rios Itararé, Cinzas, Tibagi, Pirapó) e os rios Ivaí e Piquiri; (ii) bacias afluentes da margem esquerda do rio Paraná e formadores do próprio rio Paraná (rios Paranaíba, Grande, Tietê e Paranapanema).

O critério para estimativa da vazão média específica para um determinado ano baseou-se no cálculo da média ponderada das vazões médias anuais específicas dos postos disponíveis na área considerada naquele ano. Os pesos aplicados a cada posto são proporcionais à área da bacia principal em que o posto está localizado, ou seja, considera-se que a vazão específica do posto considerado vale para toda a bacia principal. Para este fim, foram utilizados, quando possível, os postos com maiores áreas de drenagem em cada rio considerado. Aos valores estimados da vazão média anual, da média dos valores sobre um determinado período e da relação entre os valores médios de dois períodos correspondentes (antes de 1970 e depois de 1970, por exemplo) associou-se uma faixa de confiança calculada através dos pesos atribuídos a cada local com dados, através das variâncias das vazões médias anuais nos períodos correspondentes e correlações entre as séries dos postos, também em cada período considerado.

\section{Estimativa da variação das precipita- ções totais anuais após 1970 - Para a} quantificação das variações na precipitação média anual, utilizou-se um critério semelhante ao empregado para a vazão, construindo-se uma série de precipitações médias anuais para cada bacia ou área analisada. Para este fim, foram reunidos os dados de precipitações totais anuais de 193 estações pluviométricas. Para a estimativa da precipitação média em uma determinada bacia, a partir dos dados observados em locais situados dentro ou próximos da área da bacia considerada, foram interpolados os dados de precipitação média anual em um grande número de pontos internos ao contorno da bacia. O valor médio na área foi calculado pela média aritmética dos valores estimados nos diversos pontos. A estimativa dos valores pontuais foi realizada pelo método da interpolação ponderada pelo inverso do quadrado da distância. Para a estimativa da faixa de confiança empregou- 
se o mesmo critério utilizado na quantificação da vazão. Segundo esta abordagem, foram estimadas as séries de precipitações totais anuais das bacias com dados observados suficientes para estas estimativas: rio Grande, Tietê, Paranapanema e área incremental situada na margem esquerda do rio Paraná a jusante da foz do rio Paranapanema, englobando as bacias dos rios Ivaí e Piquiri.

\section{RESULTADOS}

As Tabelas 1 a 5 apresentam as probabilidades obtidas em cada teste estatístico, usando séries de dados anuais. Estas probabilidades representam os níveis máximos de significância considerando que a hipótese básica de estacionariedade é verdadeira. Valores iguais a 0,00 nestas tabelas significam probabilidades inferiores a $1 \%$.

As colunas $\overline{\mathbf{Q}}_{\mathbf{2}} / \overline{\mathbf{Q}}_{\mathbf{1}}$ e $\overline{\mathbf{P}}_{\mathbf{2}} / \overline{\mathbf{P}}_{\mathbf{1}}$ mostram, respectivamente, a relação entre as vazões ou precipitações médias entre os períodos posterior e anterior a 1970. As colunas seguintes mostram, para cada teste estatístico (Wald-Wolfowitz - WW; Cox-Stuart CS; Coeficiente de Correlação de Spearman - SP; Wilcoxon - WI; Kruskal-Wallis - KW; Mann-Kendall MK e $t$ de Student - T) a probabilidade de se observar um valor da estatística de teste igual ou maior do que o valor calculado, ou seja, quanto menor esta probabilidade, mais forte a evidência de nãoestacionariedade.

Tabela 1. Resultados. Estações fluviométricas da área incremental.

\begin{tabular}{|c|c|c|c|c|c|c|c|c|c|c|c|}
\hline Código & Rio & $\begin{array}{l}\text { Área } \\
\left(\mathrm{km}^{2}\right)\end{array}$ & Período & $\frac{\overline{\mathbf{Q}}_{2}}{\overline{\mathbf{Q}}_{1}}$ & WW & CS & SP & WI & $\mathrm{KW}$ & MK & $\mathrm{T}$ \\
\hline 63002900 & Sucuruí & 17900 & $07 / 63$ a $12 / 92$ & 1,62 & 0,00 & 0,02 & 0,00 & & & & \\
\hline 63400000 & Verde & 21800 & $11 / 63$ a 09/96 & & & 0,36 & 0,38 & & & & \\
\hline 63920000 & Pardo & 12000 & $01 / 64$ a $12 / 92$ & 1,57 & 0,00 & & 0,00 & & & & \\
\hline 63980000 & Pardo & 33300 & $10 / 63$ a 09/96 & 1,68 & 0,00 & 0,03 & 0,01 & & & & \\
\hline 64248000 & Itararé & 4997 & $07 / 31$ a $12 / 70$ & & 0,44 & 0,18 & 0,11 & & & & \\
\hline 64360000 & das Cinzas & 2015 & 06/30 a 05/96 & 1,63 & 0,01 & 0,00 & 0,00 & 0,00 & 0,00 & 0,00 & 0,00 \\
\hline 64370000 & das Cinzas & 5622 & 07/31 a 06/96 & 1,82 & 0,19 & 0,00 & 0,00 & 0,00 & 0,00 & 0,00 & 0,00 \\
\hline 64390000 & Laranjinha & 3445 & 07/31 a 07/94 & 1,85 & 0,05 & 0,04 & 0,00 & 0,00 & 0,00 & 0,00 & 0,00 \\
\hline 64440000 & Tibagi & 1340 & 08/37 a 09/67 & & 0,50 & 0,30 & 0,45 & & & & \\
\hline 64460000 & Capivari & 722 & $09 / 44$ a $02 / 96$ & 1,24 & 0,29 & 0,01 & 0,05 & 0,07 & 0,07 & 0,04 & 0,11 \\
\hline 64465000 & Tibagi & 8948 & $11 / 31$ a $05 / 96$ & 1,29 & 0,31 & 0,06 & 0,02 & 0,02 & 0,02 & 0,02 & 0,01 \\
\hline 64500000 & Tigre & 58,5 & $12 / 95$ & 1,46 & 0,01 & 0,08 & 0,00 & & & & \\
\hline 64507000 & Tibagi & 21955 & 11/31 a 06/96 & 1,40 & 0,19 & 0,00 & 0,01 & 0,01 & 0,00 & 0,01 & 0,00 \\
\hline 64550000 & Pirapó & 4627 & $11 / 67$ a 04/96 & 1,68 & 0,05 & 0,21 & 0,11 & & & & \\
\hline 64575000 & Paraná & 670000 & $10 / 63$ & 1,22 & 0,19 & 0,01 & 0,12 & & & & \\
\hline 64605000 & Brilhante & 9085 & $06 / 72$ a $12 / 91$ & & & 0,25 & 0,46 & & & & \\
\hline 64617000 & Ivinheima & 31905 & $07 / 72$ a $12 / 95$ & & 0,20 & 0,39 & 0,09 & & & & \\
\hline 64620000 & dos Pat & 1086 & $06 / 3$ & 1,29 & 0,23 & 0,04 & 0,03 & 0,05 & 0,05 & 0,02 & 0,02 \\
\hline 64625000 & Ivaí & 3572 & 06/96 & 1,16 & 0,37 & 0,25 & 0,29 & & & & \\
\hline 64645000 & Ivaí & 8600 & $09 / 65$ a 05/96 & 1,55 & 0,29 & 0,30 & 0,13 & & & & \\
\hline 64655000 & Ivaí & 12701 & 05/67 a 05/96 & 1,73 & 0,43 & 0,50 & 0,17 & & & & \\
\hline 64660000 & Corum & 3243 & $2 / 76$ & 1,95 & & 0,03 & 0,00 & & & & \\
\hline 64685000 & Ivaí & 28427 & $04 / 53$ a 05/96 & 1,36 & 0,22 & 0,50 & 0,07 & 0,01 & 0,01 & 0,09 & 0,02 \\
\hline 64690000 & Ivaí & 33087 & $12 / 65$ a $05 / 76$ & 1,86 & & 0,19 & 0,19 & & & & \\
\hline 64693000 & Ivaí & 34432 & $08 / 74$ a $02 / 96$ & & 0,19 & 0,27 & 0,46 & & & & \\
\hline 64715001 & Ama & 7252 & 06/72 a 04/96 & & 0,42 & 0,19 & 0,47 & & & & \\
\hline 64725000 & Iguatemi & 6832 & $05 / 72$ a $01 / 87$ & & & 0,36 & 0,21 & & & & \\
\hline 64775000 & Cantu & 2513 & 08/67 a 04/96 & 1,66 & 0,17 & 0,09 & 0,07 & & & & \\
\hline 64785000 & Goio-B & 1350 & & 1,82 & 0,45 & 0,09 & 0,02 & & & & \\
\hline 64790000 & Sapucaí & 535 & 01/66 a 04/96 & 2,02 & 0,23 & 0,15 & 0,00 & & & & \\
\hline 64795000 & Piquiri & 11303 & $05 / 70$ a $03 / 96$ & & 0,21 & 0,50 & 0,31 & & & & \\
\hline 64799500 & Piquiri & 12124 & $02 / 78$ a $04 / 96$ & & & 0,50 & 0,41 & & & & \\
\hline 64800000 & Piquiri & 13154 & $04 / 62$ a 01/79 & 1,33 & & 0,36 & 0,40 & & & & \\
\hline 64810000 & Goio-Er & 2424 & $04 / 96$ & 1,59 & 0,43 & 0,04 & 0,02 & & & & \\
\hline 64820000 & Piquiri & 17500 & 06/66 a 05/96 & 1,83 & 0,36 & 0,15 & 0,07 & & & & \\
\hline 64830000 & Piquiri & 20982 & $10 / 69$ a $04 / 96$ & 1,56 & 0,16 & 0,50 & 0,38 & & & & \\
\hline
\end{tabular}


Tabela 2. Resultados. Usinas hidrelétricas.

\begin{tabular}{|c|c|c|c|c|c|c|c|c|c|c|c|}
\hline Código & lome & Rio & $\begin{array}{r}\text { Área } \\
\left(\mathrm{km}^{2}\right)\end{array}$ & $\begin{array}{l}\overline{\mathbf{Q}}_{2} \\
\overline{\overline{\mathbf{Q}}_{1}}\end{array}$ & WW & CS & SP & WI & $\mathrm{KW}$ & MK & $\mathrm{T}$ \\
\hline 0160080 & mborcação & aranaíba & 29000 & 1,09 & 0,13 & 0,04 & 0,01 & 0,20 & 0,19 & 0,01 & 0,10 \\
\hline 60330080 & Jova Ponte & Araguari & 15300 & 1,09 & 0,00 & 0,04 & 0,00 & 0,25 & 0,25 & 0,00 & 0,12 \\
\hline 60610080 & Itumbiara & Paranaíba & 95000 & 1,02 & 0,05 & 0,08 & 0,05 & 0,62 & 0,61 & 0,05 & 0,32 \\
\hline 60625080 & Cachoeira Dourada & Paranaíba & 99700 & 1,02 & 0,02 & 0,08 & 0,05 & 0,62 & 0,62 & 0,05 & 0,32 \\
\hline 60877080 & São Simão & Paranaíba & 171000 & 1,08 & 0,26 & 0,04 & 0,02 & 0,18 & 0,17 & 0,02 & 0,09 \\
\hline 61061080 & Camargos & Grande & 6280 & 1,04 & 0,01 & 0,24 & 0,09 & 0,43 & 0,42 & 0,11 & 0,26 \\
\hline 61661000 & Furnas & Grande & 50464 & 1,09 & 0,05 & 0,24 & 0,18 & 0,36 & 0,35 & 0,18 & 0,11 \\
\hline 61730080 & Masc. de & Grande & 59600 & 1,05 & 0,05 & 0,24 & 0,19 & 0,58 & 0,58 & 0,18 & 0,22 \\
\hline 61731080 & Estreito & Grande & 61942 & 1,05 & 0,05 & 0,24 & 0,20 & 0,59 & 0,58 & 0,19 & 0,22 \\
\hline 61734080 & Jag & de & 62700 & 1,05 & 0,05 & 0,24 & 0,18 & 0,54 & 0,52 & 0,17 & 0,21 \\
\hline 80 & Vo & & 68800 & 1,05 & 0,05 & 0,24 & 0,17 & 0,54 & 0,53 & 0,16 & 0,21 \\
\hline 61796080 & Porto Colômbia & Grande & 78400 & 1,06 & 0,05 & 0,24 & 0,14 & 0,50 & 0,49 & 0,15 & 0,18 \\
\hline 080 & nde & & 2566 & 1,06 & 3 & 0,24 & 0,13 & 0,48 & 0,48 & 0,14 & 0,18 \\
\hline 080 & & & 4366 & 1,03 & 0 & 0,36 & 0,40 & 0,88 & 0,87 & 0,40 & 0,24 \\
\hline 9080 & do S. Oliveira & Par & 4447 & 1,04 & 0 & 0,36 & 0,37 & 0,86 & 0,85 & 0,37 & 0,24 \\
\hline 80 & Mari & & 16700 & 1,16 & 0,26 & 0,14 & 0,01 & 0,03 & 0,03 & 0,02 & 0,01 \\
\hline 080 & E. de Moraes & & 139900 & 1,18 & 0,13 & 0,14 & 0,00 & 0,01 & 0,01 & 0,01 & 0,00 \\
\hline & & & & & & & & 1 & 0 & 0 & 0,00 \\
\hline 6272 & Bar & & 32330 & 1,18 & 0,26 & 0,24 & 0,02 & 0,12 & 0,12 & 0,03 & 0,02 \\
\hline 62744080 & Souza Lima & Tietê & 35430 & 1,20 & 0,26 & 0,24 & 0,01 & 0,07 & 0,07 & 0,02 & 0,01 \\
\hline 62790080 & Ibitir & Tietê & 43500 & 1,24 & 0,26 & 0,08 & 0,00 & 0,02 & 0,02 & 0,00 & 0,00 \\
\hline 62820080 & Máı & & 57610 & 1,24 & 0,13 & 0,04 & 0,00 & 0,01 & 0,01 & 0,00 & 0,00 \\
\hline 62829580 & No & & 62300 & 1,26 & 0,26 & 0,04 & 0,00 & 0,01 & 0,01 & 0,00 & 0,00 \\
\hline 00080 & nãos & Tietê & 71510 & 1,34 & 0,03 & 0,00 & 0,00 & 0,00 & 0,00 & 0,00 & 0,00 \\
\hline 63007080 & Sou & Paran & 470000 & 1,21 & 0,00 & 0,02 & 0,00 & 0,00 & 0,00 & 0,00 & 0,00 \\
\hline 64215080 & Laydner & Par & 17800 & 1,23 & 0,05 & 0,04 & 0,01 & 0,04 & 0,04 & 0,01 & 0,01 \\
\hline 64270080 & Xavé & Paranapanema & 27500 & 1,33 & 0,13 & 0,00 & 0,00 & 0,00 & 0,00 & 0,00 & 0,00 \\
\hline 64332080 & N. Garcez & & 38765 & 1,36 & 0,00 & 0,00 & 0,00 & 0,00 & 0,00 & 0,00 & 0,00 \\
\hline 64516080 & Capivara & Paranapanema & 85000 & 1,45 & 0,01 & 0,00 & 0,00 & 0,00 & 0,00 & 0,00 & 0,00 \\
\hline 64535080 & & & 88000 & 1,44 & 0,00 & 0,00 & 0,00 & 0,00 & 0,00 & 0,00 & 0,00 \\
\hline 64571080 & Rosana & Paranapanema & 99000 & 1,45 & 0,00 & 0,00 & 0,00 & 0,00 & 0,00 & 0,00 & 0,00 \\
\hline 64918980 & Itaipu & Paraná & 820000 & 1,36 & 0,00 & 0,00 & 0,00 & 0,00 & 0,00 & 0,00 & 0,00 \\
\hline
\end{tabular}

Para os locais onde a série histórica de dados resulta em sub-amostras para o período antes e depois de 1970, de tamanho inferior a 15 anos, não foram aplicados os testes que exigem a divisão da série em sub-amostras (Wilcoxon, Kruskal-Wallis e $t$ de Student), o que justifica a existência de falhas nestas tabelas.

Os resultados referentes ao teste de Tendência Polinomial não são apresentados, mas acompanharam a tendência geral dos demais testes. Nestas tabelas estão apresentados apenas os resultados dos testes unilaterais, e no caso do teste exigir a divisão da amostra em sub-amostras, foi adotado o ano de 1970.

Nessas tabelas observa-se que os vários testes produzem resultados diferentes para um mesmo local. Isto se deve ao fato de que cada teste analisa a série de uma forma própria e distinta.

\section{Critério geral de análise dos resultados dos testes estatísticos}

Com o objetivo de facilitar a análise do grande número de resultados obtidos foi definido um critério geral de análise. Este critério resultou das considerações a seguir apresentadas:

i. foram utilizados apenas os resultados dos testes unilaterais, o que é mais compatível com a hipótese que está sendo verificada, de aumento das vazões ou precipitações médias. A utilização dos testes bilaterais 
Tabela 3. Resultados. Estações fluviométricas dos rios Paranaíba, Grande, Tietê e Paranapanema.

\begin{tabular}{llrlcccccccc}
\hline Código & Rio & $\begin{array}{r}\text { Área } \\
\left(\mathrm{km}^{2}\right)\end{array}$ & Período & $\begin{array}{c}\overline{\mathbf{Q}}_{2} \\
\overline{\mathbf{Q}}_{1}\end{array}$ & WW & CS & SP & WI & KW & MK & T \\
\hline 60040000 & São Marcos & 10659 & $01 / 50$ a $12 / 89$ & 1,03 & 0,05 & 0,50 & 0,31 & 0,94 & 0,93 & & 0,43 \\
60170000 & Paranaíba & 29300 & $01 / 50$ a $12 / 89$ & 1,04 & 0,05 & 0,50 & 0,22 & 0,79 & 0,77 & & 0,41 \\
60235000 & Araguari & 3970 & $01 / 50$ a $12 / 91$ & 0,94 & 0,00 & 0,25 & 0,33 & 0,41 & 0,41 & & 0,24 \\
60320002 & Quebra-Anzol & 8490 & $05 / 52$ a $12 / 89$ & 1,05 & 0,09 & 0,24 & 0,13 & 0,94 & 0,94 & & 0,35 \\
60545000 & Corumbá & 21248 & $01 / 50$ a $12 / 89$ & 0,97 & 0,50 & 0,50 & 0,32 & 0,60 & 0,59 & & 0,31 \\
60880000 & Paranaíba & 171000 & $01 / 50$ a $12 / 89$ & 1,07 & 0,16 & 0,50 & 0,07 & 0,48 & 0,46 & & 0,28 \\
61012000 & Grande & 2226 & $01 / 31$ a $12 / 84$ & 1,04 & 0,20 & 0,42 & 0,39 & & & 0,37 & \\
61834000 & Pardo & 10679 & $01 / 41$ a $03 / 91$ & 1,28 & 0,03 & 0,15 & 0,01 & 0,01 & 0,01 & 0,01 & 0,00 \\
61884002 & Moji-Guaçu & 3834 & $12 / 44$ a $03 / 88$ & 1,27 & 0,18 & 0,19 & 0,07 & 0,13 & 0,12 & 0,09 & 0,02 \\
61925000 & Pardo & 33740 & $07 / 58$ a $03 / 91$ & 1,13 & 0,50 & 0,23 & 0,20 & & & & \\
62545000 & Sorocaba & 5531 & $08 / 43$ a $12 / 90$ & 1,25 & 0,23 & 0,50 & 0,06 & 0,22 & 0,21 & 0,06 & 0,06 \\
62632000 & Jaguari & 3394 & $06 / 43$ a 04/88 & 1,00 & 0,38 & 0,26 & 0,38 & 0,55 & 0,53 & 0,38 & 0,48 \\
62680000 & Atibaia & 2305 & $06 / 44$ a $04 / 88$ & 0,93 & 0,22 & 0,10 & 0,07 & 0,13 & 0,13 & 0,05 & 0,29 \\
62715000 & Piracicaba & 11040 & $06 / 43$ a 04/88 & 1,04 & 0,38 & 0,42 & 0,45 & 0,79 & 0,76 & 0,43 & 0,37 \\
62885000 & Tietê & 69792 & $10 / 37$ a $12 / 78$ & 1,12 & 0,02 & 0,41 & 0,33 & & & 0,30 & \\
63160000 & Aguapei & 3670 & $09 / 46$ a 06/90 & 1,51 & 0,01 & 0,00 & 0,00 & 0,00 & 0,00 & 0,00 & 0,00 \\
64065000 & Itapetininga & 1524 & $11 / 47$ a $12 / 89$ & 1,20 & 0,32 & 0,13 & 0,09 & 0,24 & 0,23 & 0,09 & 0,07 \\
64120100 & Apiaí & 2024 & $10 / 33$ a $12 / 90$ & 1,14 & 0,18 & 0,43 & 0,17 & 0,40 & 0,39 & 0,16 & 0,08 \\
64315000 & Pardo & 3407 & $04 / 55$ a $12 / 89$ & 1,28 & 0,00 & 0,01 & 0,01 & & & & \\
\hline
\end{tabular}

significaria apenas trabalhar com outro limite de significância;

ii. foram utilizados apenas os resultados para o nível de significância de $5 \%$, por considerar que a avaliação de outros limites apenas agregaria informações para análise de sensibilidade do problema; além disso, os níveis de significância máximos resultantes de cada teste foram considerados na análise como um indicativo da intensidade do fenômeno, mesmo quando superiores ao limite de $5 \%$;

iii. o ano de 1970 foi adotado como referência para a separação de amostras, quando necessário. Este critério visa apenas simplificar as análises, não significando o estabelecimento de nenhuma conclusão a priori sobre o período exato do início do fenômeno;

iv. elegeu-se o teste do Coeficiente de Correlação de Spearman como o mais consistente em seus resultados e o menos sujeito a efeitos indesejáveis, como, por exemplo, a detecção de nãoestacionariedade por influência de picos localizados na série. Não foram desconsiderados os resultados dos demais testes, apenas decidiu-se atribuir uma importância maior aos resultados obtidos por este teste, por ser recomendado na literatu- ra e pela maior compatibilidade dos resultados com o fenômeno a ser analisado.

\section{Vazões da área incremental}

Os dados descritivos das séries de vazões utilizadas podem ser examinados na Tabela 1 e a localização das mesmas estações pode ser vista na Figura 1.

Aplicando-se o critério geral de análise aos resultados da área incremental, conclui-se que os resultados dos testes aplicados às séries anuais de dados fluviométricos fornecem fortes indicações pela sua não-estacionariedade, no sentido do aumento de vazões no período mais recente. As justificativas são as seguintes: (i) $50 \%$ dos postos estudados apresentaram pelo menos um teste estatístico positivo (indicando não-estacionariedade); (ii) $35 \%$ dos testes realizados apresentaram resultados positivos; (iii) dos postos que apresentaram pelo menos um teste positivo, $63 \%$ dos testes realizados foram positivos, resultando uma média de 3,1 testes positivos por posto, para uma média de 4,3 testes realizados por posto. Apenas dois postos apresentaram um teste positivo. Todos os restantes apresentaram dois ou mais; (iv) analisando-se os resultados por tipo de teste, $42 \%$ dos testes do Coeficiente de Spearman foram positivos; 
(v) a análise dos níveis máximos de significância para o teste de Spearman confirma as conclusões anteriores. A média dos níveis máximos para o teste é de 15,3\%. Dos postos com testes positivos, $53 \%$ possuem valores inferiores a $0,5 \%$ e $73 \%$ apresentaram valores menores que $2 \%$. E $64 \%$ dos postos apresentaram valores menores que $15 \%$.

Outra forma de avaliar os resultados consiste na análise da probabilidade obtida quando se aplica aos dados disponíveis uma distribuição binomial. Esta probablidade representa a chance de se observar um determinado número de sucessos para o número de ensaios disponíveis. No caso em questão, para o teste de Spearman, a probabilidade de ocorrerem 15 sucessos em 36 ensaios, cada sucesso com probabilidade de 0,05, é muito pequena e igual a $0,5787.10^{-10}$, confirmando as conclusões de não-estacionariedade das séries de vazões da área incremental.

Tabela 4. Resultados. Estações pluviométricas do Estado do Paraná.

\begin{tabular}{|c|c|c|c|c|c|c|c|c|c|c|}
\hline Código & Rio & Período & $\frac{\overline{\mathbf{P}}_{2}}{\overline{\mathbf{P}_{1}}}$ & WW & CS & SP & WI & $\mathrm{KW}$ & MK & $\mathrm{T}$ \\
\hline 02349031 & Salto do Itararé & $01 / 39$ a 12/79 & 1,18 & 0,08 & 0,41 & 0,26 & & & 0,24 & \\
\hline 02349032 & Siqueira Campos & $01 / 37$ a $12 / 80$ & 0,81 & 0,02 & 0,14 & 0,07 & & & 0,07 & \\
\hline 02349033 & Tomazina & $07 / 37$ a 09/96 & 1,06 & 0,18 & 0,50 & 0,44 & 0,25 & 0,24 & 0,32 & 0,42 \\
\hline 02349034 & Wenceslau Braz & 01/39 a 12/82 & 1,07 & 0,50 & 0,42 & 0,25 & & & 0,28 & \\
\hline 02349066 & Ponte Melo Peixoto & $01 / 39$ a $12 / 80$ & 1,57 & 0,18 & 0,50 & 0,18 & & & 0,23 & \\
\hline 02350000 & Jataizinho & 01/38 a 07/96 & 1,16 & 0,18 & 0,07 & 0,01 & 0,01 & 0,01 & 0,01 & 0,05 \\
\hline 02350002 & Andirá & $10 / 45$ a 09/96 & 1,13 & 0,08 & 0,28 & 0,11 & 0,09 & 0,09 & 0,11 & 0,28 \\
\hline 02350016 & Salto Fiu & 07/55 a 12/95 & 1,15 & 0,26 & 0,25 & 0,07 & & & & \\
\hline 02351008 & Apucaran & $11 / 64$ a 12/95 & 1,12 & 0,43 & 0,30 & 0,30 & & & & \\
\hline 02352000 & Porto Paraíso do Norte & a $09 / 96$ & 1,05 & 0,44 & 0,33 & 0,07 & 0,87 & 0,86 & 0,05 & 0,47 \\
\hline 02352013 & Porto Flórida & 05/64 a 06/94 & 1,21 & 0,23 & 0,50 & 0,27 & & & & \\
\hline 02353001 & Santa Izabel do Ivaí & $10 / 57$ a $07 / 96$ & 1,06 & 0,44 & 0,18 & 0,41 & & & & \\
\hline 02353002 & Bals & 09/96 & 1,12 & 0,08 & 0,50 & 0,21 & & & & \\
\hline 02449006 & Bals & $06 / 96$ & 1,23 & 0,01 & 0,01 & 0,00 & & & & \\
\hline 02449019 & Jaguariaíva & 10/17 a 08/96 & 1,17 & 0,28 & 0,09 & 0,01 & 0,00 & 0,00 & 0,01 & 0,00 \\
\hline 02450002 & Tibagi & $04 / 38$ a 12/95 & 1,24 & 0,07 & 0,02 & 0,02 & 0,00 & 0,00 & 0,02 & 0,00 \\
\hline 02450006 & Sal & 09/96 & 1,07 & 0,45 & 0,12 & 0,32 & 0,37 & 0,37 & 0,37 & 0,33 \\
\hline 02450010 & Cast & 2/94 & 1,00 & 0,41 & 0,00 & 0,07 & 0,76 & 0,76 & 0,07 & 0,50 \\
\hline 02451012 & Rib. Raposo Tavares & 09/65 a 12/95 & 1,33 & 0,29 & 0,30 & 0,36 & & & & \\
\hline 02451013 & Pitan & $12 / 95$ & 1,19 & 0,23 & 0,30 & 0,02 & & & & \\
\hline 02451014 & & 08/96 & 1,07 & 0,32 & 0,41 & 0,34 & & & 0,32 & \\
\hline 02451017 & Portc & 08/65 a 12/95 & 1,11 & 0,36 & 0,50 & 0,47 & & & & \\
\hline 02452009 & Ubiratã & $04 / 65$ a 12/95 & 1,24 & 0,07 & 0,15 & 0,01 & & & & \\
\hline 013 & $\mathrm{No}$ & 5 & 1,14 & 0,42 & 0,50 & 0,06 & & & & \\
\hline 02452014 & Man & 2/95 & 1,17 & 0,36 & 0,50 & 0,07 & & & & \\
\hline 02452016 & Palm & $04 / 65$ a 12/95 & 1,32 & 0,03 & 0,02 & 0,00 & & & & \\
\hline 02453004 & Usina As & 09/66 a 12/95 & 1,09 & 0,42 & 0,40 & 0,20 & & & & \\
\hline 06 & Palo & & 1,00 & 0,50 & 0,13 & 0.43 & & & & \\
\hline 02453009 & Portc & 2/95 & 0,92 & 0,01 & 0,03 & 0,01 & & & & \\
\hline 02453010 & Formosa do Oeste & 04/67 a 12/95 & 1,01 & 0,13 & 0,21 & 0,35 & & & & \\
\hline 02453012 & & & 1,24 & 0,23 & 0,15 & 0,01 & & & & \\
\hline 02454009 & Guaíra & $2 / 94$ & 1,12 & 0,29 & 0,06 & 0,12 & & & & \\
\hline 02550000 & Patos & 05/37 a 12/95 & 1,12 & 0,12 & 0,23 & 0,06 & 0,15 & 0,15 & 0,06 & 0,16 \\
\hline 02550006 & Ivaí & 12/12 a 03/96 & 1,12 & 0,20 & 0,37 & 0,12 & 0,01 & 0,01 & 0,08 & 0,01 \\
\hline 02550024 & & & 1,05 & 0,38 & 0,19 & 0,12 & 0,38 & 0,36 & 0,11 & 0,21 \\
\hline & Gua & $01 / 85$ & 1,13 & 0,10 & 0,29 & 0,06 & & & 0,06 & \\
\hline 02552000 & Cam & 08/49 a 09/96 & 1,06 & 0,19 & 0,27 & 0,50 & 0,66 & 0,65 & 0,47 & 0,40 \\
\hline 02552007 & Laran & 10/64 a 12/95 & 1,15 & 0,43 & 0,30 & 0,18 & & & & \\
\hline & Fozd & & 1,00 & 0,08 & 0,33 & 0,35 & & & 0,32 & \\
\hline 02554007 & Colégio Medianeira & 07/62 a 05/88 & 0,96 & 0,21 & 0,13 & 0,12 & & & & \\
\hline
\end{tabular}


Tabela 5. Resultados. Estações pluviométricas do Estado de São Paulo.

\begin{tabular}{|c|c|c|c|c|c|c|c|c|c|c|}
\hline Código & Rio & Período & $\frac{\overline{\mathbf{P}}_{2}}{\overline{\mathbf{P}}_{1}}$ & WW & CS & SP & WI & $\mathrm{KW}$ & MK & $\mathrm{T}$ \\
\hline 02047018 & Faz. Santa Cecília & $08 / 37$ a $12 / 90$ & 1,19 & 0,11 & 0,02 & 0,01 & 0,01 & 0,01 & 0,02 & 0,01 \\
\hline 02047025 & Orlândia & $03 / 39$ a $12 / 90$ & 1,09 & 0,45 & 0,12 & 0,24 & 0,33 & 0,33 & 0,27 & 0,08 \\
\hline 02047027 & Faz. Conquista & $10 / 40$ a $12 / 90$ & 1,17 & 0,50 & 0,12 & 0,08 & 0,05 & 0,05 & 0,09 & 0,01 \\
\hline 02047028 & Usina Esmeril & $08 / 37$ a $12 / 90$ & 1,30 & 0,17 & 0,04 & 0,00 & 0,00 & 0,00 & 0,01 & 0,00 \\
\hline 02048015 & Barretos & $01 / 36$ a $12 / 90$ & 1,31 & 0,05 & 0,03 & 0,00 & 0,00 & 0,00 & 0,00 & 0,00 \\
\hline 02048021 & Colina & $12 / 38$ a $12 / 90$ & 1,18 & 0,24 & & 0,02 & 0,01 & 0,01 & 0,02 & 0,00 \\
\hline 02048023 & Morro Agudo & $08 / 40$ a $12 / 90$ & 1,17 & 0,20 & 0,00 & 0,01 & 0,01 & 0,01 & 0,02 & 0,00 \\
\hline 02048027 & Faz. Marambaia & $12 / 40$ a $12 / 90$ & 1,13 & 0,24 & 0,03 & 0,04 & 0,08 & 0,07 & 0,05 & 0,04 \\
\hline 02049010 & Cosmorama & $11 / 41$ a $12 / 90$ & 1,37 & 0,12 & 0,01 & 0,00 & 0,00 & 0,00 & 0,00 & 0,00 \\
\hline 02049013 & Onda Verde & $02 / 43$ a $12 / 90$ & 1,25 & 0,44 & 0,01 & 0,00 & 0,00 & 0,00 & 0,00 & 0,00 \\
\hline 02147006 & Ribeirão Preto & $07 / 39$ a $12 / 90$ & 1,18 & 0,24 & 0,05 & 0,04 & 0,02 & 0,02 & 0,04 & 0,00 \\
\hline 02147023 & Mococa & $07 / 40$ a $12 / 90$ & 1,13 & 0,39 & 0,21 & 0,04 & 0,19 & 0,18 & 0,05 & 0,07 \\
\hline 02148012 & Est. Experimental & $01 / 36$ a $12 / 90$ & 1,30 & 0,29 & 0,22 & 0,00 & 0,00 & 0,00 & 0,00 & 0,01 \\
\hline 02148029 & Mutuca & $08 / 36$ a $12 / 90$ & 1,21 & 0,05 & 0,00 & 0,00 & 0,01 & 0,01 & 0,00 & 0,00 \\
\hline 02148033 & Matão & $08 / 41$ a $12 / 90$ & 1,19 & 0,02 & 0,01 & 0,00 & 0,01 & 0,01 & 0,00 & 0,00 \\
\hline 02148060 & Us. Gavião Peixoto & $01 / 36$ a $12 / 90$ & 1,14 & 0,39 & 0,13 & 0,01 & 0,04 & 0,03 & 0,01 & 0,01 \\
\hline 02148061 & Usina Chibarro & $09 / 31$ a $12 / 90$ & 1,15 & 0,45 & 0,01 & 0,01 & 0,02 & 0,02 & 0,01 & 0,01 \\
\hline 02148086 & lbate & $04 / 39$ a $12 / 90$ & 1,17 & 0,16 & 0,01 & 0,00 & 0,01 & 0,01 & 0,00 & 0,01 \\
\hline 02148106 & Cândido Rodrigues & $08 / 41$ a $12 / 90$ & 1,24 & 0,44 & 0,15 & 0,01 & 0,01 & 0,01 & 0,02 & 0,01 \\
\hline 02149007 & Barbosa & $01 / 36$ a $10 / 91$ & 1,12 & 0,25 & 0,13 & 0,01 & 0,03 & 0,03 & 0,01 & 0,01 \\
\hline 02149017 & Guaiçara & $05 / 37$ a $12 / 90$ & 1,06 & 0,06 & 0,42 & 0,45 & 0,92 & 0,91 & 0,42 & 0,39 \\
\hline 02150010 & Araçatuba & $06 / 43$ a $12 / 90$ & 1,17 & 0,44 & 0,11 & 0,02 & 0,03 & 0,03 & 0,03 & 0,01 \\
\hline 02150013 & Guararapes & $04 / 44$ a $12 / 90$ & 1,37 & 0,04 & 0,05 & 0,00 & 0,00 & 0,00 & 0,00 & 0,00 \\
\hline 02150026 & Alto Alegre & $12 / 39$ a $12 / 90$ & 1,14 & 0,28 & 0,35 & 0,32 & 0,14 & 0,13 & 0,38 & 0,05 \\
\hline 02151013 & Faz. Santo André & $07 / 47$ a $12 / 90$ & 1,19 & 0,14 & 0,01 & 0,04 & 0,02 & 0,02 & 0,05 & 0,01 \\
\hline 02246013 & Itapira & $10 / 40$ a $12 / 90$ & 1,19 & 0,20 & 0,05 & 0,09 & 0,08 & 0,08 & 0,10 & 0,01 \\
\hline 02246019 & Serra Negra & $12 / 36$ a $12 / 90$ & 1,26 & 0,45 & 0,09 & 0,00 & 0,02 & 0,02 & 0,00 & 0,00 \\
\hline 02246035 & Vargem & $09 / 37$ a $12 / 91$ & 1,10 & 0,09 & 0,50 & 0,04 & 0,56 & 0,54 & 0,04 & 0,21 \\
\hline 02246037 & Salto Grande & $01 / 36$ a $12 / 91$ & 1,16 & 0,02 & 0,22 & 0,10 & 0,06 & 0,06 & 0,10 & 0,01 \\
\hline 02247002 & Vila Carmem & $01 / 36$ a $12 / 90$ & 1,12 & 0,34 & 0,16 & 0,21 & 0,20 & 0,20 & 0,26 & 0,05 \\
\hline 02247003 & a Geraldo & $10 / 36$ a $12 / 90$ & 1,19 & 0,29 & 0,22 & 0,01 & 0,01 & 0,01 & 0,01 & 0,00 \\
\hline 02247004 & Analândia & $01 / 37$ a $12 / 91$ & 1,26 & 0,00 & 0,00 & 0,00 & 0,00 & 0,00 & 0,00 & 0,00 \\
\hline 02247015 & Grauna & $02 / 37$ a 10/91 & 1,06 & 0,50 & 0,35 & 0,04 & 0,11 & 0,11 & 0,05 & 0,03 \\
\hline 02247017 & Faz. Belmonte & $11 / 36$ a $12 / 90$ & 1,16 & 0,34 & 0,16 & 0,12 & 0,34 & 0,33 & 0,10 & 0,05 \\
\hline 02247022 & Santa Gertrudes & $11 / 41$ a $12 / 91$ & 1,23 & 0,44 & 0,15 & 0,01 & 0,01 & 0,01 & 0,02 & 0,01 \\
\hline 02247046 & Campinas & $01 / 41$ a $10 / 91$ & 1,06 & 0,08 & 0,05 & 0,01 & 0,12 & 0,12 & 0,01 & 0,04 \\
\hline 02247075 & Usina Americana & $01 / 37$ a $12 / 91$ & 1,09 & 0,39 & 0,35 & 0,18 & 0,39 & 0,38 & 0,22 & 0,09 \\
\hline 02248005 & Ribeirão Bonito & $01 / 36$ a $11 / 90$ & 1,29 & 0,00 & 0,06 & 0,03 & 0,00 & 0,00 & 0,07 & 0,00 \\
\hline 02248014 & Barra Ma & $10 / 37$ a $12 / 90$ & 1,22 & 0,11 & 0,09 & 0,01 & 0,03 & 0,03 & 0,01 & 0,00 \\
\hline 02248016 & Dois Córr & $01 / 36$ a $12 / 90$ & 1,13 & 0,21 & 0,50 & 0,07 & 0,12 & 0,12 & 0,09 & 0,03 \\
\hline 02248045 & Usina Três Saltos & $08 / 36$ a $12 / 90$ & 1,17 & 0,14 & 0,50 & 0,02 & 0,05 & 0,05 & 0,23 & 0,02 \\
\hline 02249006 & Garça & $12 / 38$ a $12 / 90$ & 1,31 & 0,10 & & 0,00 & 0,00 & 0,00 & 0,00 & 0,00 \\
\hline 02249008 & Marília & $07 / 39$ a $12 / 90$ & 1,30 & 0,24 & 0,01 & 0,00 & 0,00 & 0,00 & 0,00 & 0,00 \\
\hline 02249018 & Fernão Dias & $07 / 36$ a $12 / 90$ & 1,37 & 0,01 & 0,00 & 0,00 & 0,00 & 0,00 & 0,00 & 0,00 \\
\hline 02249019 & Piratininga & $01 / 39$ a $12 / 90$ & 1,31 & 0,24 & 0,00 & 0,00 & 0,00 & 0,00 & 0,00 & 0,00 \\
\hline 02249023 & Cabrália Paulista & $12 / 38$ a $12 / 90$ & 1,38 & 0,03 & 0,01 & 0,00 & 0,00 & 0,00 & 0,00 & 0,00 \\
\hline 02250007 & Oriente & $12 / 38$ a $12 / 90$ & 1,36 & 0,10 & & 0,00 & 0,00 & 0,00 & 0,00 & 0,00 \\
\hline 02250023 & Usin & $09 / 38$ a $12 / 90$ & 1,22 & 0,20 & 0,01 & 0,00 & 0,00 & 0,00 & 0,00 & 0,00 \\
\hline 02346003 & Vinhedo & $09 / 36$ a $12 / 90$ & 1,32 & 0,03 & 0,03 & 0,00 & 0,00 & 0,00 & 0,01 & 0,00 \\
\hline 02346020 & Mairipora & $01 / 37$ a $12 / 90$ & 1,09 & 0,44 & 0,35 & 0,08 & 0,58 & 0,58 & 0,06 & 0,09 \\
\hline 02346030 & Bom Sucesso & $05 / 40$ a $12 / 90$ & 1,10 & 0,08 & 0,50 & 0,42 & 0,44 & 0,43 & 0,48 & 0,09 \\
\hline 02346045 & Luz (Estação) & $01 / 00$ a $12 / 90$ & 1,08 & 0,00 & 0,12 & 0,04 & 0,31 & 0,31 & 0,04 & 0,10 \\
\hline 02346053 & São Caet. do Sul & $01 / 37$ a $12 / 90$ & 1,15 & 0,45 & 0,04 & 0,01 & 0,04 & 0,03 & 0,01 & 0,01 \\
\hline 02346060 & Pedro Beicht & $11 / 36$ a $12 / 90$ & 1,10 & 0,14 & 0,22 & 0,11 & 0,35 & 0,35 & 0,12 & 0,11 \\
\hline 02347017 & Cesário Lange & $12 / 39$ a $12 / 90$ & 1,11 & 0,20 & 0,21 & 0,18 & 0,67 & 0,66 & 0,13 & 0,18 \\
\hline 02347026 & Tatuí & $07 / 39$ a $12 / 90$ & 1,15 & 0,44 & 0,12 & 0,03 & 0,15 & 0,15 & 0,03 & 0,03 \\
\hline 02347043 & Ibiúna & $11 / 39$ a $12 / 90$ & 1,22 & 0,00 & 0,12 & 0,00 & 0,14 & 0,14 & 0,01 & 0,04 \\
\hline 02348008 & Avaré & $07 / 39$ a $12 / 90$ & 1,30 & 0,03 & 0,00 & 0,00 & 0,00 & 0,00 & 0,00 & 0,00 \\
\hline 02348016 & Faz. Aterradinho & $10 / 39$ a $12 / 90$ & 1,31 & 0,01 & 0,00 & 0,00 & 0,00 & 0,00 & 0,00 & 0,00 \\
\hline 02349025 & Riversul & $06 / 39$ a $12 / 90$ & 1,19 & 0,10 & 0,05 & 0,01 & 0,03 & 0,03 & 0,01 & 0,01 \\
\hline 02447001 & Usina Turvinho & $10 / 36$ a $12 / 90$ & 1,21 & 0,14 & 0,13 & 0,00 & 0,01 & 0,01 & 0,00 & 0,00 \\
\hline
\end{tabular}


As simulações Monte Carlo realizadas com as séries fluviométricas de três postos com correlação serial significativa confirmaram plenamente os resultados dos testes estatísticos. As correlações em série destes postos são baixas, bem próximas do limite de significância. Portanto, os resultados dos testes estatísticos podem ser considerados como válidos para todos os postos analisados.

Além do critério geral de análise, foi também analisada a distribuição espacial dos resultados. Pelas análises da distribuição espacial dos resultados, todas as bacias apresentam postos com testes positivos. O maior número de postos com testes positivos encontra-se na região Nordeste do Paraná, mas esta região é onde encontra-se a maioria dos postos com séries mais longas. Provavelmente, se a distribuição espacial dos postos com séries mais longas fosse mais homogênea, um número maior de postos com resultados positivos seria encontrado nas demais bacias analisadas.

Foram analisados os dados de vazões mínimas de 10 postos fluviométricos localizados no Estado do Paraná, com dados suficientes para a divisão dos períodos em duas partes, antes e depois de 1970. As principais informações referentes a estes postos encontram-se na Tabela 1. A Tabela 6 apresenta as vazões médias mínimas de estiagem, para 5 durações de estiagem selecionadas: $7,15,30,60$ e 120 dias. A mesma tabela também mostra o resultado da aplicação do teste $t$ de Student às vazões médias referentes aos períodos antes e após 1970. A última coluna da tabela apresenta a seguinte convenção: "0" significa que a hipótese básica foi aceita (a série é estacionária) e "1" significa o contrário (não pode ser aceita a hipótese de estacionariedade), para um nível de significância de 5\%. Pela análise dos dados mostrados na Tabela 6, percebe-se que todos os 10 postos analisados apresentaram aumento na vazão mínima após 1970 para as 5 durações de estiagens analisadas. Destes 10 postos, 8 foram reprovados no teste $t$ de igualdade de médias dos períodos anteriores e posteriores a 1970.

aumento médio de vazão mínima, incluindo todos os postos e durações foi de $43 \%$ em relação ao período anterior a 1970.

\section{Vazões naturais de usinas}

Os resultados dos testes estatísticos e simulações realizadas com os dados de 32 usinas localizadas na bacia do rio Paraná foram obtidos usando-se as séries de vazões naturais de 1931 a 1994 que constam no banco de dados do setor
Tabela 6. Resultados.

Análise de vazões mínimas.

\begin{tabular}{|c|c|c|c|c|c|}
\hline \multirow[t]{2}{*}{ Código } & \multirow{2}{*}{$\begin{array}{c}\text { Duração } \\
\text { (dias) }\end{array}$} & \multicolumn{2}{|c|}{ Média $\left(\mathrm{m}^{3} / \mathrm{s}\right)$} & \multirow{2}{*}{$\frac{\overline{\mathbf{Q}}_{\mathbf{2}}}{\overline{\mathbf{Q}}_{1}}$} & \multirow{2}{*}{$\begin{array}{l}\text { Teste } t \\
(95 \%)\end{array}$} \\
\hline & & $\begin{array}{c}\text { Antes } \\
70 \\
\end{array}$ & $\begin{array}{c}\text { Após } \\
70\end{array}$ & & \\
\hline \multirow{5}{*}{64360000} & 7 & 6,46 & 10,00 & 1,55 & 1 \\
\hline & 15 & 7,01 & 10,79 & 1,54 & 1 \\
\hline & 30 & 7,92 & 12,11 & 1,53 & 1 \\
\hline & 60 & 10,24 & 14,42 & 1,41 & 1 \\
\hline & 120 & 19,21 & 19,30 & 1,00 & 0 \\
\hline \multirow{5}{*}{64370000} & 7 & 10,36 & 18,72 & 1,81 & 1 \\
\hline & 15 & 11,77 & 19,54 & 1,66 & 1 \\
\hline & 30 & 12,81 & 21,90 & 1,71 & 1 \\
\hline & 60 & 15,30 & 27,67 & 1,81 & 1 \\
\hline & 120 & 19,82 & 41,29 & 2,08 & 1 \\
\hline \multirow{5}{*}{64390000} & 7 & 5,89 & 8,93 & 1,52 & 1 \\
\hline & 15 & 6,52 & 9,39 & 1,44 & 1 \\
\hline & 30 & 6,90 & 11,23 & 1,63 & 1 \\
\hline & 60 & 8,09 & 14,96 & 1,85 & 1 \\
\hline & 120 & 12,40 & 23,59 & 1,90 & 1 \\
\hline \multirow{5}{*}{64460000} & 7 & 2,50 & 3,21 & 1,28 & 1 \\
\hline & 15 & 2,73 & 3,55 & 1,30 & 1 \\
\hline & 30 & 3,12 & 4,13 & 1,32 & 1 \\
\hline & 60 & 3,79 & 5,08 & 1,34 & 1 \\
\hline & 120 & 6,94 & 7,19 & 1,04 & 0 \\
\hline \multirow{5}{*}{64465000} & 7 & 31,08 & 44,31 & 1,43 & 1 \\
\hline & 15 & 35,77 & 47,71 & 1,33 & 1 \\
\hline & 30 & 38,97 & 51,87 & 1,33 & 1 \\
\hline & 60 & 47,83 & 63,37 & 1,32 & 1 \\
\hline & 120 & 67,76 & 91,34 & 1,35 & 1 \\
\hline \multirow{5}{*}{64500000} & 7 & 0,425 & 0,550 & 1,29 & 1 \\
\hline & 15 & 0,442 & 0,592 & 1,34 & 1 \\
\hline & 30 & 0,471 & 0,661 & 1,40 & 1 \\
\hline & 60 & 0,525 & 0,731 & 1,39 & 1 \\
\hline & 120 & 0,594 & 0,916 & 1,54 & 1 \\
\hline \multirow{5}{*}{64507000} & 7 & 72,42 & 123,91 & 1,71 & 1 \\
\hline & 15 & 78,70 & 134,22 & 1,71 & 1 \\
\hline & 30 & 88,92 & 151,85 & 1,71 & 1 \\
\hline & 60 & 105,38 & 178,80 & 1,70 & 1 \\
\hline & 120 & 147,89 & 246,89 & 1,67 & 1 \\
\hline \multirow{5}{*}{64620000} & 7 & 2,91 & 3,49 & 1,20 & 0 \\
\hline & 15 & 3,31 & 3,83 & 1,16 & 0 \\
\hline & 30 & 3,74 & 4,41 & 1,18 & 0 \\
\hline & 60 & 5,09 & 5,90 & 1,16 & 0 \\
\hline & 120 & 7,94 & 10,78 & 1,36 & 1 \\
\hline \multirow{5}{*}{64625000} & 7 & 8,00 & 8,91 & 1,11 & 0 \\
\hline & 15 & 8,99 & 9,86 & 1,10 & 0 \\
\hline & 30 & 10,97 & 12,25 & 1,12 & 0 \\
\hline & 60 & 15,73 & 16,87 & 1,07 & 0 \\
\hline & 120 & 24,40 & 32,69 & 1,34 & 0 \\
\hline \multirow{5}{*}{64685000} & 7 & 104,05 & 140,82 & 1,35 & 1 \\
\hline & 15 & 111,44 & 152,28 & 1,37 & 1 \\
\hline & 30 & 125,22 & 169,31 & 1,35 & 1 \\
\hline & 60 & 156,04 & 212,25 & 1,36 & 1 \\
\hline & 120 & 218,82 & 304,44 & 1,39 & 1 \\
\hline
\end{tabular}


elétrico. Os dados descritivos das séries de vazões utilizadas podem ser examinados na Tabela 2 e a localização das mesmas estações pode ser vista na Figura 2. Todas as análises realizadas sobre as séries consideraram o ano hidrológico de outubro a setembro do ano seguinte.

A análise da consistência destas séries não foi objeto do presente estudo. Porém, pelo número relativamente grande de locais de usinas avaliados e pela extensão geográfica das bacias correspondentes, espera-se que, em termos gerais, os resultados obtidos representem uma inferência importante do fenômeno de tendência nas vazões médias da região, apesar do desconhecimento da qualidade destas séries.

Com base nos resultados obtidos pelos testes estatísticos e simulações Monte Carlo, podese concluir que as séries de vazões naturais das usinas localizadas nos rios Tietê, Paranapanema e Paraná a jusante da foz do rio Grande são nãoestacionárias. A distribuição espacial dos locais com indicativos de não-estacionariedade mostrouse clara e coerente com a hipótese de que o fenômeno seria mais acentuado nas bacias localizadas mais próximas da usina de Itaipu. Ao longo de um mesmo rio, notou-se também que o fenômeno se agrava mais no sentido de montante para jusante na bacia. Este fato pode ser notado claramente nos resultados apresentados para os rios Grande, Tietê, Paranapanema e Paraná. As usinas José Ermírio de Morais, no rio Grande, Ibitinga, Mário L. Leão, Nova Avanhandava e Três Irmãos, no rio Tietê, Armando Laydner, Xavantes, Lucas Nogueira Garcez, Capivara, Taquaruçu e Rosana, no rio Paranapanema, Ilha Solteira, Jupiá e Itaipu, no rio Paraná, são as que apresentam o maior número de testes indicando a existência de séries de vazões não-estacionárias. As usinas de Nova Ponte, no rio Araguari, e Marimbondo, no rio Grande, também apresentam vários resultados indicando nãoestacionariedade. Outras usinas apresentam alguns testes positivos, porém em menor escala.

Analisando-se apenas os resultados do teste do Coeficiente de Spearman aplicados aos valores médios anuais, nota-se que $55 \%$ dos locais apresentaram resultados positivos para o limite de significância de $5 \%$. Dos locais com testes positivos, $64 \%$ apresentaram níveis de significância abaixo de $1 \%$. A compilação dos resultados dos demais testes confirma as conclusões apresentadas acima e estão coerentes com os resultados do teste do Coeficiente de Spearman.

A probabilidade obtida da distribuição binomial aplicada aos resultados do teste de Spearman é muito pequena, igual a $0,9209 \cdot 10^{-21}$, confirmando as conclusões anteriores.
As simulações Monte Carlo realizadas com as séries de 11 usinas que apresentaram correlação serial significativa confirmaram plenamente os resultados dos testes estatísticos.

\section{Vazões médias das bacias dos rios Paranaíba, Grande, Tietê e Paranapanema}

Com o intuito de reunir mais informações que permitissem ampliar as análises de estacionariedade das séries fluviométricas, foram aplicados testes estatísticos aos dados de 19 estações fluviométricas distribuídas ao longo das bacias dos rios Paranaíba, Grande, Tietê e Paranapanema. Os dados descritivos das séries de vazões utilizadas podem ser examinados na Tabela 3 e a localização das mesmas estações pode ser vista na Figura 2. Todas as análises realizadas sobre estas séries consideraram o ano hidrológico de outubro a setembro do ano seguinte.

Os dados dessas estações foram coletados ao final do estudo. Dado o reduzido prazo para levantamento dos dados, as estações selecionadas apresentam períodos de observações até 1990, aproximadamente. O objetivo da análise destes dados seria apoiar as conclusões obtidas para as análises das séries de vazões naturais das usinas localizadas nestas mesmas bacias. No entanto, a distribuição espacial das 19 estações fluviométricas analisadas não é conveniente, pois a maioria dos postos localiza-se nas cabeceiras das respectivas bacias, portanto com áreas de drenagem relativamente pequenas se comparadas às bacias principais. Adicionalmente, parte das estações possui períodos de observação relativamente curtos para as análises pretendidas, razões pelas quais os resultados foram parcialmente comprometidos.

Das 19 estações, apenas 8 possuem períodos de observações suficientes para a aplicação de todos os testes estatísticos. Das estações analisadas, apenas 3 apresentaram indicativos razoavelmente seguros da não-estacionariedade das séries. Estas estações são as seguintes: 61834000 (Clube de Regatas, no rio Pardo, afluente do rio Grande), 63160000 (Fazenda Bom Retiro, no rio Aguapeí) e 64315000 (Águas de Santa Bárbara, no rio Pardo, afluente do rio Paranapanema). Outras estações apresentaram resultados positivos isolados.

A análise em separado dos resultados do teste do Coeficiente de Spearman mostra que os níveis máximos de significância de alguns locais 


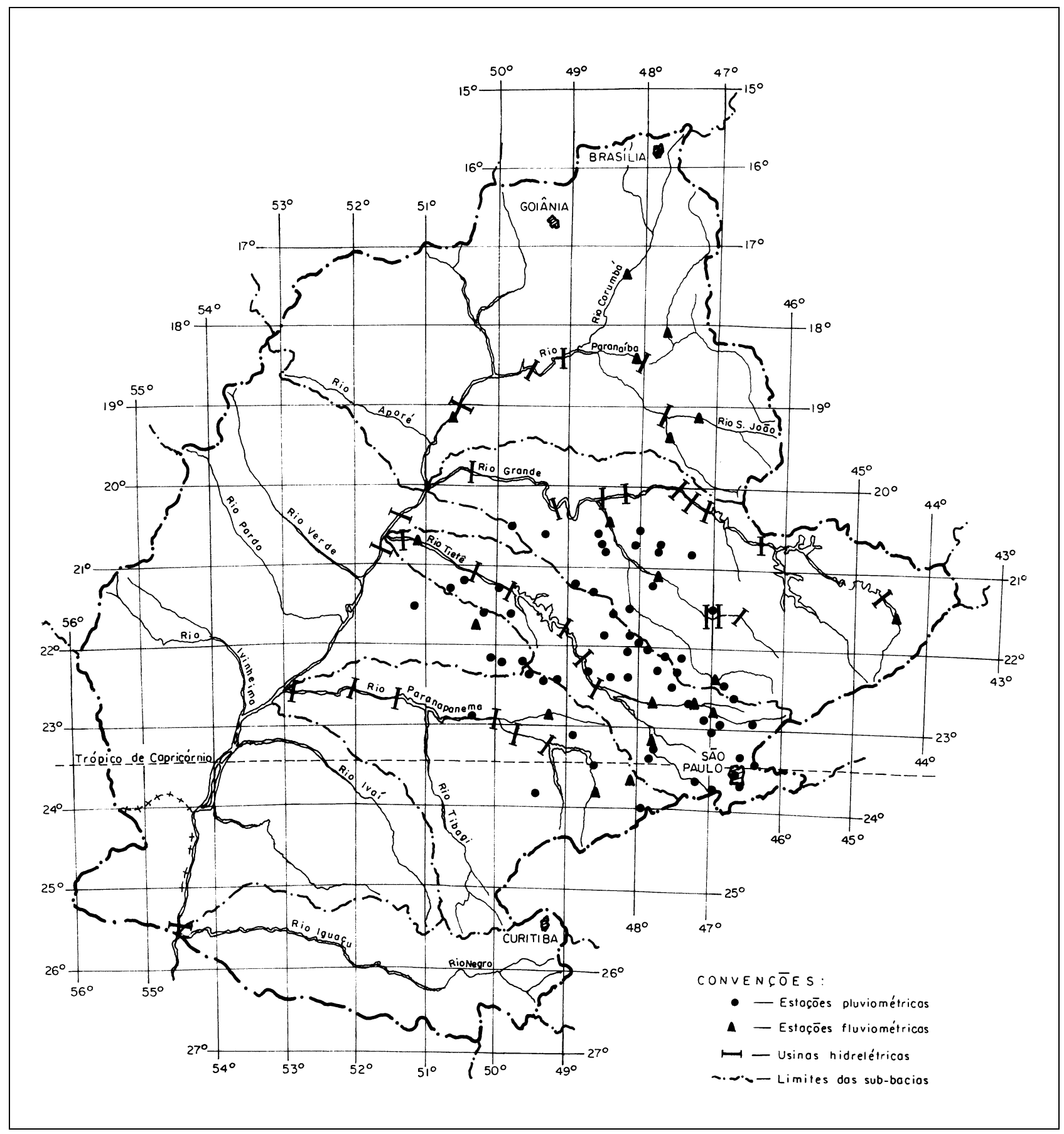

Figura 2. Localização dos postos pluviométricos, fluviométricos e usinas.

são pouco maiores que o limite de 5\%. Dos 19 locais analisados, 8 postos (42\%) apresentaram limites máximos de significância inferiores a 10\%, com média de $4,7 \%$ e desvio padrão $3,4 \%$.

Dada a extensão limitada destas informações, não seria aconselhável extrair conclusões mais gerais a partir dos dados analisados. Apenas é possível comentar que os poucos locais analisados que apresentaram indicativos de não- estacionariedade estão localizados em bacias que apresentaram sinais neste sentido na análise dos dados de vazões naturais de usinas. Neste particular, cabe observar que dos 6 postos localizados na bacia do rio Paranaíba, apenas 1 apresentou resultado positivo e em apenas um teste (WaldWolfowitz). Os postos que apresentaram limites máximos de significância inferiores a $10 \%$ no teste do Coeficiente de Spearman estão distribuídos de 
forma aproximadamente homogênea nas demais bacias, com exceção do posto 60880000 - Fazenda Santa Fé, no rio Paranaíba, localizado a jusante da usina São Simão. Este resultado, ainda que de forma bastante precária, devido ao período relativamente curto e também devido à influência dos volumes de regularização dos reservatórios de montante, está coerente com os resultados dos testes das vazões naturais da usina São Simão.

A probabilidade obtida da distribuição binomial para os resultados do teste de Spearman é, neste caso, bem maior e igual a 0,0533, o que confirma a dificuldade encontrada para a análise das séries de vazões destas bacias.

\section{Séries pluviométricas de postos no Estado do Paraná}

Seguindo os mesmos critérios aplicados para a análise das séries fluviométricas da área incremental e analisando-se os resultados dos testes estatísticos e das séries de precipitações diárias, algumas conclusões podem ser obtidas a respeito da estacionariedade das séries pluviométricas dos postos localizados na área incremental dentro do Estado do Paraná. Os dados descritivos das séries de precipitação utilizadas podem ser examinados na Tabela 4 e a localização das mesmas estações pode ser vista na Figura 1.

Pelo critério geral de análise, conclui-se que os resultados dos testes aplicados às séries de dados pluviométricos anuais no Estado do Paraná fornecem indicações de não-estacionariedade no sentido de aumento de precipitações médias no período mais recente, porém de forma mais discreta, se comparada aos resultados dos testes sobre as vazões. As justificativas são as seguintes:

i. $30 \%$ dos postos estudados apresentaram pelo menos um teste estatístico positivo (indicando não-estacionariedade);

ii. $17 \%$ de todos os testes realizados foram positivos;

iii. $53 \%$ dos testes aplicados aos postos que apresentaram pelo menos um resultado positivo foram positivos, perfazendo uma média de 2,6 testes por posto para uma média de 4,6 testes aplicados por posto;

iv. a análise dos níveis de significância do teste do Coeficiente de Spearman resultou em uma média de $17,6 \%$, superior à encontrada para os postos fluviométricos, mas $23 \%$ dos postos apresentaram níveis inferiores a $5 \%$ e $43 \%$ dos postos com níveis abaixo de $10 \%$. De todos os postos, $15 \%$ apresentam sinais inequívocos de nãoestacionariedade, com níveis máximos de significância inferiores a $1 \%$, enquanto que $20 \%$ apresentam valores abaixo de $2 \%$. A dificuldade de se concluir a respeito da não-estacionariedade das séries pluviométricas do Estado do Paraná é confirmada pela probabilidade bem maior $\left(0,01089.10^{-2}\right)$ obtida da distribuição binomial aplicada aos resultados do teste de Spearman, se comparada aos resultados das vazões na mesma área.

A distribuição espacial dos testes positivos de cada posto indica que o maior número de postos com indicativos de não-estacionariedade localiza-se no Nordeste do Estado do Paraná. Novamente, como no caso da análise das vazões, a maior concentração de postos com séries mais longas encontra-se nesta região. Portanto, se a distribuição espacial dos postos com séries mais longas fosse mais homogênea, provavelmente um número maior de postos com resultados positivos seria encontrado nas demais bacias analisadas. Os dados apresentam alguma inconsistência espacial, com postos com fortes indicativos de nãoestacionariedade circundados por postos sem nenhum sinal aparente.

A avaliação dos resultados das análises de estacionariedade na freqüência e intensidade da precipitação diária foi dificultada por diversos fatores: (i) a grande dispersão apresentada nos gráficos dos eventos analisados, provocada principalmente pelo erro amostral resultante de amostras com tamanhos insuficientes; (ii) os gráficos dos ajustes realizados para a obtenção de um padrão sazonal dentro do ano, quando comparados para os dois sub-períodos das séries, nem sempre permitem uma conclusão objetiva a respeito do aumento ou diminuição de uma determinada grandeza (freqüência ou intensidade), pois este aumento ou diminuição pode ocorrer em uma determinada época do ano apenas, para alguns casos; (iii) a distribuição espacial dos postos analisados não resultou ideal, devido à escassez de postos com dados suficientes para a divisão em duas sub-amostras. A maior parte das estações analisadas localizam-se no nordeste do Estado do Paraná.

Tendo em vista tais dificuldades, realizouse uma análise visual dos resultados, observandose o comportamento dos gráficos obtidos após o ajuste dos modelos teóricos a cada série pluviométrica diária. Segundo este critério, verifica-se que na análise das amostras sub-divididas no ano de 1970 ocorre predomínio do aumento de fre- 
qüência dos eventos, acompanhada por uma conseqüente diminuição da intensidade média da chuva, em $53 \%$ dos postos analisados. Apenas $8 \%$ dos postos apresentou comportamento contrário, ou seja, diminuição de freqüência dos eventos, acompanhada por aumento de intensidade, e $39 \%$ não permitiram nenhuma conclusão. Este resultado pode indicar uma tendência no sentido do aumento de freqüência e diminuição da intensidade da precipitação diária para a região, mas certamente um volume maior de dados diários seria necessário para a obtenção de uma conclusão mais segura. A grande variação amostral das estimativas demonstra claramente a necessidade de séries mais longas para a obtenção de resultados mais confiáveis. Tal conclusão, ainda que levante dúvidas quanto ao insuficiente comprimento das séries analisadas, conduz a conjecturas sobre o efeito desta alteração no comportamento das vazões. Um dos possíveis efeitos de um aumento de freqüência e diminuição de intensidade dos eventos diários seria uma melhor manutenção do estado de umidade das bacias, repercutindo em um menor déficit do armazenamento sub-superficial. Tal efeito poderia provocar um aumento nas vazões mínimas das bacias em que a alteração fosse verificada.

Dos 10 postos fluviométricos cujas vazões mínimas foram analisadas, 8 deles apresentam posto pluviométrico na mesma localização ou bastante próximo. Destes 8 postos pluviométricos, 6 apresentaram indicações de alterações nos eventos diários, no sentido de aumento de freqüência e diminuição de intensidade após 1970. Estes postos são os seguintes: 02349033 (Tomazina), 02350000 (Jataizinho), 02350002 (Andirá), 02352000 (Porto Paraíso do Norte), 02450002 (Tibagi) e 02450009 (Bom Jardim). Para todos estes locais ocorreram aumentos significativos nas vazões mínimas após 1970. Além disso, é interessante notar que os 2 postos que não foram reprovados no teste de igualdade de médias, 64620000 (rio dos Patos) e 64625000 (Tereza Cristina, no rio Ivaí) são representativos de uma área onde ocorreram dois resultados indefinidos na análise da chuva diária: 02550000 (rio dos Patos) e 02550006 (Ivaí). Ou seja, para estes locais não foi possível determinar se houve alteração de comportamento na precipitação diária. Apesar da concordância dos resultados, convém ressaltar que a indicação de alterações de comportamento nas chuvas diárias representa apenas uma, dentre várias outras causas que poderiam influenciar no fenômeno do aumento de vazões mínimas.

\section{Séries pluviométricas de postos no Estado de São Paulo}

Com o intuito de reunir mais informações que permitissem ampliar as análises de estacionariedade das séries pluviométricas, foram aplicados testes estatísticos aos dados de 61 estações pluviométricas localizadas no Estado de São Paulo, distribuídas ao longo das bacias dos rios Grande, Tietê e Paranapanema. Os dados descritivos das séries de precipitação utilizadas podem ser examinados na Tabela 5 e a localização das mesmas estações pode ser vista na Figura 2. Todas as análises realizadas sobre estas séries consideraram o ano hidrológico de outubro a setembro do ano seguinte.

Os dados destas estações foram coletados ao final do estudo. Dado o reduzido prazo para levantamento dos dados, as estações selecionadas apresentam períodos de observações até 1990, aproximadamente. A maior parte das estações possui um período de observações de aproximadamente 50 anos. O objetivo da análise destes dados seria ampliar a área original do estudo, englobando o Estado de São Paulo, como forma de buscar confirmações para as conclusões sobre o comportamento das precipitações, que dispõem em geral de séries muito curtas na maior parte do Estado do Paraná, prejudicando a clareza dos resultados dos testes estatísticos.

Pela homogeneidade dos períodos históricos, quase a totalidade dos postos permitiram a aplicação de todos os testes estatísticos. O grande número de testes positivos mostra que a maioria dos postos analisados apresenta comportamento de séries não-estacionárias.

Ao contrário do que ocorreu na análise dos resultados dos testes aplicados às vazões naturais, em que os resultados positivos ficaram mais concentrados nas bacias mais a jusante, mais próximas à Itaipu, os resultados para as estações pluviométricas de São Paulo apresentaram resultados positivos distribuídos de forma aproximadamente homogênea por toda a área em que as estações estão localizadas.

Os níveis de significância apresentados para o teste do Coeficiente de Spearman foram, em geral, bastante baixos. Das estações analisadas, apenas $15 \%$ apresentaram níveis acima de $10 \%$. Os $85 \%$ restantes apresentaram uma média de apenas $1,8 \%$ com desvio-padrão de $2,5 \%$. Do total de testes realizados para o Coeficiente de Spearman, $77 \%$ resultaram positivos para o nível de significância de $5 \%$. A probabilidade obtida da distribuição binomial aplicada aos resultados do 
teste de Spearman é muito pequena, igual a $0,7801.10^{-48}$, confirmando as conclusões de nãoestacionariedade destas séries.

A distribuição espacial dos resultados positivos e negativos não permite concluir que em uma determinada área da região onde estão localizados os postos em estudo exista uma predominância maior do fenômeno. Da mesma forma como ocorreu para as estações pluviométricas do Paraná, alguns postos em que todos os testes concluem pela estacionariedade da série estão circundados por outros postos onde ocorre o contrário.

\section{Variação das vazões médias anuais após 1970}

A Tabela 7 mostra o resultado da quantificação da variação das vazões médias anuais, em termos de vazões específicas, para as áreas e bacias analisadas, considerando o período histórico de 1931 a 1994 e separadamente 1931-1970 e 1971-1994. Juntamente com cada resultado, apresenta-se a faixa de confiança correspondente a dois desvios padrão.

Para as bacias dos rios Paranaíba, Grande, Tietê e Paranapanema o cálculo foi baseado apenas nas séries de vazões naturais das usinas situadas mais próximas das respectivas exutórias, ou seja, usinas São Simão, José Ermírio de Morais, Três Irmãos e Rosana, respectivamente. Portanto, para estas bacias, devido ao desconhecimento da qualidade das séries de vazões naturais utilizadas, os resultados obtidos devem ser considerados com reservas.

Os resultados para a bacia incremental, conforme definido anteriormente, engloba os afluentes da margem esquerda do rio Paranapanema: Itararé, Cinzas, Tibagi, Pirapó e as bacias dos rios Ivaí e Piquiri do rio Paraná. As estimativas para esta área foram realizadas com os dados dos postos localizados mais próximos da foz de cada um dos rios considerados. Também não foi possível obter estimativas para as estações situadas na margem direita do rio Paraná, devido à má quali- dade dos dados de algumas estações e também devido à insuficiência de dados anteriores a 1970.

A Tabela 8 mostra a variação das vazões médias anuais após 1970 nas áreas analisadas. Os valores apresentados são os resultados da divisão dos valores de vazão média obtidos após 1970 pelos valores médios referentes ao período anterior a 1970. Juntamente com cada resultado, apresenta-se a faixa de confiança correspondente a dois desvios padrão.

Tabela 8. Variação da vazão média anual após 1970.

\begin{tabular}{lccc}
\hline & & 1970 & \\
Bacia & $-2 \mathrm{~S}$ & & $+2 \mathrm{~S}$ \\
\hline Paranaíba & 0,94 & 1,08 & 1,22 \\
Grande & 1,01 & 1,18 & 1,35 \\
Tietê & 1,11 & 1,34 & 1,56 \\
Paranapanema & 1,21 & 1,45 & 1,70 \\
Incremental & 1,16 & 1,44 & 1,71 \\
\hline
\end{tabular}

Pelos resultados apresentados, levando-se em consideração o desconhecimento da qualidade das séries de vazões naturais das bacias dos rios Paranaíba, Grande, Tietê e Paranapanema, notase que, com exceção da bacia do rio Paranaíba, após 1970 ocorreram significativos aumentos nas vazões médias anuais nas bacias consideradas, e este efeito é maior nas bacias mais próximas de Itaipu. Este resultado é compatível com os resultados obtidos nas análises de estacionariedade, onde as bacias dos rios Paranapanema e Tietê apresentaram os maiores indicativos de nãoestacionariedade.

\section{Variação das precipitações totais anuais após 1970}

A Tabela 9 mostra os resultados da quantificação da variação na precipitação média anual para as bacias dos rios Grande, Tietê, Paranapa-

Tabela 7. Estatísticas das séries de vazões médias específicas (1/s.km²).

\begin{tabular}{lrrrrrrrrr}
\hline & \multicolumn{3}{c}{$1931-94$} & \multicolumn{3}{c}{$1931-70$} & & \multicolumn{3}{c}{$1971-94$} \\
Bacia & $-2 \mathrm{~S}$ & & $+2 \mathrm{~S}$ & $-2 \mathrm{~S}$ & & $+2 \mathrm{~S}$ & $-2 \mathrm{~S}$ & & $+2 \mathrm{~S}$ \\
\hline Paranaíba & 12,87 & 13,73 & 14,60 & 12,24 & 13,33 & 14,43 & 12,87 & 14,39 & 15,91 \\
Grande & 13,75 & 14,79 & 15,83 & 12,70 & 13,84 & 14,99 & 14,41 & 16,37 & 18,33 \\
Tietê & 9,79 & 10,71 & 11,63 & 8,62 & 9,51 & 10,40 & 10,96 & 12,71 & 14,45 \\
Paranapanema & 11,33 & 12,50 & 13,67 & 9,60 & 10,69 & 11,78 & 13,42 & 15,53 & 17,64 \\
Incremental & 15,04 & 16,78 & 18,52 & 12,66 & 14,42 & 16,17 & 17,71 & 20,72 & 23,72 \\
\hline
\end{tabular}


Tabela 9. Estatísticas das séries de precipitações médias anuais (mm).

\begin{tabular}{lccccccccc}
\hline & \multicolumn{3}{c}{$1936-90$} & \multicolumn{3}{c}{$1936-70$} & \multicolumn{3}{c}{$1971-90$} \\
Bacia & $-2 \mathrm{~S}$ & & $+2 \mathrm{~S}$ & $-2 \mathrm{~S}$ & & $+2 \mathrm{~S}$ & $-2 \mathrm{~S}$ & $+2 \mathrm{~S}$ \\
\hline Grande & 1327 & 1393 & 1459 & 1238 & 1310 & 1381 & 1427 & 1538 & 1649 \\
Tietê & 1262 & 1323 & 1384 & 1190 & 1253 & 1316 & 1335 & 1446 & 1558 \\
Paranapanema & 1309 & 1370 & 1431 & 1227 & 1294 & 1362 & 1397 & 1504 & 1610 \\
Incremental $^{1519}$ & 1596 & 1672 & 1454 & 1542 & 1630 & 1562 & 1690 & 1817 \\
Paranapanema* $_{\text {Incremental }^{*}}$ & 1337 & 1394 & 1452 & 1259 & 1326 & 1392 & 1415 & 1509 & 1603 \\
\hline
\end{tabular}

* Período 1931 a 1994

nema e área incremental, juntamente com a faixa de confiança correspondente a dois desvios padrão. Para as bacias dos rios Grande e Tietê, o período de dados disponíveis para análise permitiu reconstituir a série de precipitações médias anuais de 1936 a 1990. Para as bacias do rio Paranapanema e incremental o período é 1931 a 1994.

Analisando-se os resultados apresentados na Tabela 10 nota-se que o efeito do aumento na precipitação média anual após 1970 é maior nas bacias mais distantes da usina de Itaipu, portanto aumentando de jusante para montante ao longo do rio Paraná. As menores diferenças foram obtidas na área incremental a jusante da foz do rio Paranapanema (apenas margem esquerda), englobando as bacias dos rios Ivaí e Piquiri, seguida pelos resultados da bacia do rio Paranapanema. Nestas duas bacias, o limite inferior da faixa de confiança chega a atingir valores inferiores à unidade, portanto colocando em dúvida se o aumento de precipitação média ocorre em toda a extensão das mesmas. Para as duas bacias restantes, os valores obtidos foram todos no sentido de aumento da precipitação, sendo que as maiores diferenças foram detectadas na bacia do rio Grande. Este resultado apresenta-se compatível com os testes estatísticos aplicados primeiramente às estações pluviométricas localizadas no Paraná e, na segunda fase do estudo, às estações pluviométricas localizadas em São Paulo.

\section{Relações entre precipitação e vazão média}

Um resultado de interesse para o estudo seria a estimativa do percentual de aumento de vazões que seria esperado descontando-se o acréscimo devido ao aumento da precipitação. Para esta finalidade, foram calculados os aumentos de precipitação e vazão após 1970 para as bacias analisadas, em milímetros, para facilitar a compa- ração. A Tabela 11 mostra as diferenças entre as precipitações médias $\left(P_{2}-P_{1}\right)$ e vazões médias $\left(Q_{2}-Q_{1}\right)$ dos dois períodos, onde os índices "1" $\mathrm{e}$ "2" indicam "até 1970" e "após 1970", respectivamente. Nota-se que os acréscimos de vazão podem ser justificados pelos aumentos na precipitação apenas para as áreas situadas a montante na bacia do rio Paraná em Itaipu. Para as bacias situadas mais a jusante (Paranapanema e área incremental, principalmente) o aumento de vazão é incompatível com o aumento da precipitação, indicando que outros fatores interferem no processo.

Tabela 10. Variação da

precipitação média anual após 1970.

\begin{tabular}{|c|c|c|c|}
\hline \multirow[t]{2}{*}{ Bacia } & \multicolumn{3}{|c|}{1970} \\
\hline & $-2 S$ & & $+2 S$ \\
\hline Grande & 1,07 & 1,17 & 1,28 \\
\hline Tietê & 1,05 & 1,15 & 1,26 \\
\hline Paranapanema & 1,06 & 1,16 & 1,26 \\
\hline Incremental & 0,99 & 1,10 & 1,20 \\
\hline Paranapanema* & 1,05 & 1,14 & 1,23 \\
\hline Incremental $^{*}$ & 0,99 & 1,08 & 1,18 \\
\hline
\end{tabular}

*Período 1931 a 1994

Nas colunas seguintes da Tabela 11 são mostrados os coeficientes de deflúvio médios (relação entre vazão e precipitação média) calculados para os dois períodos, mostrando que houve um acréscimo no percentual de precipitação transformado em vazão. Calculando-se um novo acréscimo de vazão, considerando-se o percentual de transformação chuva-vazão atual (após 1970), mas com a precipitação média do período anterior a 1970, obtém-se uma estimativa do acréscimo de vazões, excluindo-se a participação do aumento nas precipitações. Estes valores encontram-se na última coluna da Tabela 11, ao lado dos percentuais observados em cada uma das bacias. Portanto, 
Tabela 11. Relações entre a precipitação e a vazão (antes e após 1970).

\begin{tabular}{lcccccc}
\hline Bacia & $\begin{array}{c}\mathrm{P}_{2}-\mathrm{P}_{1} \\
(\mathrm{~mm})\end{array}$ & $\begin{array}{c}\mathrm{Q}_{2}-\mathrm{Q}_{1} \\
(\mathrm{~mm})\end{array}$ & $\mathrm{Q}_{1} / \mathrm{P}_{1}$ & $\mathrm{Q}_{2} / \mathrm{P}_{2}$ & $\begin{array}{c}\mathrm{Q}_{2} / \mathrm{Q}_{1} \\
\text { total }\end{array}$ & $\begin{array}{l}\mathrm{Q}_{2} / \mathrm{Q}_{1} \\
\mathrm{P} \text { cte. }\end{array}$ \\
\hline Grande & 228 & 80 & 0,33 & 0,34 & 1,18 & 1,01 \\
Tietê & 193 & 101 & 0,24 & 0,28 & 1,34 & 1,16 \\
Paranapanema* $^{*}$ & 183 & 153 & 0,25 & 0,32 & 1,45 & 1,28 \\
Incremental $^{*}$ & 127 & 199 & 0,29 & 0,39 & 1,44 & 1,33 \\
\hline
\end{tabular}

* Período 1931 a 1994

levando-se em conta as grandes simplificações implícitas nestes resultados, nota-se que na bacia do rio Grande o aumento na chuva foi responsável por quase toda a variação na vazão, enquanto que na bacia do rio Paranapanema e área incremental, mesmo que a precipitação média se mantivesse nos níveis observados até 1970, os aumentos de vazão resultantes poderiam ser da ordem de $30 \%$, se forem considerados os coeficientes de transformação chuva-vazão observados após 1970.

\section{ANÁLISES COMPLEMENTARES}

Na tentativa de elucidar os fenômenos detectados, de não homogeneidade das séries de precipitação e vazão, sob pontos de vista físico, hidrológico e meteorológico, incluindo-se também os possíveis efeitos resultantes das alterações de uso do solo ao longo do tempo, foram realizadas as análises complementares a seguir apresentadas.

\section{Estimativa da variação da evapotranspiração real}

Com o objetivo de auxiliar nas análises de tendência das séries de precipitações e vazões foi estimada a evapotranspiração real pelo Balanço Hídrico e pelo Modelo CRAE (Morton, 1976). Deseja-se, por meio da variação na evapotranspiração real, buscar a inter-relação entre os efeitos detectados e as possíveis causas físicas.

Pelo Balanço Hídrico, foram obtidas as evapotranspirações reais para as bacias dos rios das Cinzas, Laranjinha, Capivari, Tibagi, dos Patos e Ivaí, localizadas no Estado do Paraná, para os períodos antes e depois de 1960.

Pelo Modelo CRAE, ("Complementary Relationship Areal Evapotranspiration") foram obtidas evapotranspirações reais, a partir dos dados das Normais Climatológicas (Brasil, 1969 e Brasil, 1992), para os postos 02047017 (Franca), 02346129 (Santos) e 02347117 (São Paulo) no
Estado de São Paulo, e 02450010 (Castro), 02549006 (Curitiba) e 02649021 (rio Negro) no Estado do Paraná.

Os resultados obtidos pelo Balanço Hídrico, para os períodos antes e depois de 1960, mostram que para as bacias analisadas no Estado do Paraná, as evapotranspirações apresentaram uma diminuição de $10 \%$ em média, no segundo período. Este resultado é coerente com as mudanças ocorridas no uso do solo e cobertura vegetal. À medida em que a cobertura vegetal de maior porte, predominantemente florestas, é substituída por vegetação de menor porte, como pastagens e culturas anuais ou perenes, ocorre uma diminuição da interceptação, aumento do escoamento superficial e conseqüentemente uma queda na evapotranspiração real.

Os resultados de evapotranspiração real obtidos pelo Modelo CRAE indicam uma diminuição para o período após 1960, para todos os postos analisados, confirmando os resultados do Balanço Hídrico.

\section{Efeito de alterações de uso do solo}

Avaliações preliminares das alterações de uso do solo (Rocha, 1997) que ocorreram a partir da época da colonização do Norte e Noroeste do Paraná (década de 50 em diante) mostram que praticamente toda a cobertura florestal nativa foi removida, sendo substituída em grande parte por pastagens e culturas anuais. Estas mudanças podem explicar a diminuição da evapotranspiração verificada, pois o volume de água correspondente à interceptação e transpiração da floresta pode ter contribuído para aumentar o escoamento superficial e o aumento do nível do lençol freático das bacias correspondentes. Avaliações dos tipos de solos, profundidade e características físicas dos mesmos no norte e noroeste do Paraná, e os programas de conservação de solos e manejo integrado de bacias implantado no Paraná em épocas mais recentes, permitem concluir que as 
práticas atuais de manejo agrícola no Estado têm contribuído de forma consistente na manutenção da umidade do solo, aumento da capacidade de infiltração e diminuição da erosão.

Avaliações do potencial de erosão em uma bacia piloto no Oeste do Paraná (Rocha, 1997) mostram que a erosão potencial está abaixo dos limites toleráveis, portanto, não havendo erosão significativa, a quantidade de água que seria o veículo da erosão na forma de escoamento superficial tende a infiltrar e aumentar os níveis do lençol freático, contribuindo para o aumento da vazão.

\section{Análise de fatores meteorológicos}

Os resultados de estudos climáticos recentes sugerem que pode haver um componente de mudança climática em dados de temperatura e precipitação. Contudo, é possível que as tendências detectadas nas séries pluviométricas analisadas, em geral com períodos de observação bem menores que 100 anos, sejam parte de uma variabilidade secular embutida nos dados (Grimm, 1997). Estudos indicam que a variabilidade interdecadal, responsável por variações nãoantropogênicas com ciclos da ordem de várias décadas parece ser responsável por quase toda a variação ocorrida após as décadas de 60 e 70 . A variação detectada nessa época é muito forte para ser apenas uma tendência devido a mudanças climáticas, as quais só podem ser detectadas ao longo de um considerável período de tempo. A variabilidade interdecadal parece estar associada, em grande parte, à variabilidade dos eventos El Niño. A variabilidade interdecadal se manifesta através de eventos El Niño mais freqüentes e/ou mais intensos durante um período e de menos intensos e/ou mais fracos noutro período. Tendo em vista que a região de interesse apresenta significativa influência de eventos El Niño sobre suas precipitações, é possível concluir que há também influência da variação interdecadal de El Niño.

\section{CONCLUSÕES}

\section{Análises de estacionariedade das séries de vazões}

Área incremental - As principais conclusões obtidas a partir das análises realizadas com os dados fluviométricos da área incremental são as seguintes: (i) as séries são não-estacionárias, com aumento de vazões médias após 1970; (ii) o maior número de postos com séries não-estacionárias localiza-se no Nordeste do Paraná, provavelmente por ser a região onde estão localizados os postos com séries mais longas; (iii) as vazões mínimas de estiagem com durações entre 7 e 120 dias apresentaram aumentos significativos no período mais recente.

Vazões naturais de usinas - As principais conclusões obtidas a partir das análises realizadas com as séries de vazões naturais das principais usinas a montante de Itaipu são as seguintes: (i) as séries de vazões naturais dos rios Tietê, Paranapanema e Paraná (a jusante do rio Grande) são não-estacionárias, com aumento de vazões médias após 1970; (ii) o fenômeno aumenta de intensidade no sentido de montante para jusante.

\section{Postos fluviométricos nos rios Paranaíba, Grande, Tietê e Paranapa-} nema - As principais conclusões obtidas a partir das análises realizadas com os dados fluviométricos localizados nos rios Paranaíba, Grande, Tietê e Paranapanema são as seguintes: (i) uma parcela considerável das séries apresentaram alguns sinais de não-estacionariedade; (ii) os postos que apresentaram não-estacionariedade estão mais concentrados nas bacias dos rios Grande, Tietê e Paranapanema.

\section{Variação das vazões médias após}

1970 - As principais conclusões obtidas a partir da estimativa da variação das vazões são as seguintes: (i) foram detectados aumentos de vazões em todas as bacias; (ii) à exceção da bacia do rio Paranaíba, todas as outras bacias apresentaram acréscimos significativos; (iii) os aumentos médios após 1970 são os seguintes: Paranaíba (8\%), Grande (18\%), Tietê (34\%), Paranapanema (45\%) e incremental (44\%); (iv) o aumento de vazões é amplificado de montante para jusante; (v) as maiores alterações ocorreram após 1970; (vi) análises das vazões mínimas de postos da área incremental detectaram um aumento médio de vazão de $43 \%$ após 1970, considerando-se durações de estiagem entre 7 e 120 dias de duração.

\section{Análises de estacionariedade das séries de precipitações}

Postos pluviométricos do Estado do Paraná - As principais conclusões obtidas a 
partir das análises realizadas com os dados pluviométricos localizados no Paraná são as seguintes: (i) foram detectadas indicações de nãoestacionariedade, no sentido de aumento das precipitações médias após 1970; (ii) o maior número de postos com séries não-estacionárias localiza-se no Nordeste do Paraná, provavelmente por ser a região onde estão localizados os postos com séries mais longas; (iii) há indicativos de que pode ter havido aumento de freqüência e diminuição de intensidade nos eventos pluviais diários e esta alteração de comportamento pode ter contribuído para o aumento de vazões mínimas detectado.

\section{Postos pluviométricos do Estado de}

São Paulo - As principais conclusões obtidas a partir das análises realizadas com os dados pluviométricos localizados em São Paulo são as seguintes: (i) a grande maioria das séries analisadas são não-estacionárias, no sentido de aumento das precipitações médias após 1970; (ii) o fenômeno ocorreu em toda a área onde estão distribuídos os postos.

\section{Variação das precipitações médias}

após 1970 - As principais conclusões obtidas a partir da estimativa da variação das precipitações após 1970 são as seguintes: (i) foram detectados aumentos de precipitação média anual em todas as bacias; (ii) a área incremental de Itaipu apresentou o menor aumento, entre as bacias analisadas; (iii) os aumentos médios após 1970 são os seguintes: Grande $(17 \%)$, Tietê $(15 \%)$, Paranapanema $(14 \%)$ e incremental (8\%); (iv) o aumento de precipitações aparentemente é amplificado de jusante para montante, de forma inversa ao ocorrido para as vazões.

\section{Considerações finais}

Os aumentos da precipitação detectados parecem estar associados a flutuações naturais de mais baixa freqüência, chamadas variações interdecadais, que ocorrem em ciclos da ordem de várias décadas. As variabilidades interdecadais estão associadas à variabilidade dos eventos El Niño, sendo que a região de interesse apresenta significativa influência de eventos El Niño sobre suas precipitações.

Os aumentos de precipitação podem justificar o aumento de vazões para as regiões situadas nas áreas de montante da bacia do rio Paraná em Itaipu. Para as bacias situadas mais a jusante (Paranapanema e área incremental, principalmente) o aumento de vazão é incompatível com o aumento de precipitação, indicando que outros fatores, como a alteração de uso do solo, interferem no processo.

Avaliações preliminares considerando a hipótese de que a precipitação média não houvesse aumentado após 1970 mostram que os aumentos de vazão resultantes poderiam ser da ordem de $30 \%$ nas bacias do rio Paranapanema e área incremental, se forem considerados os coeficientes de transformação chuva-vazão observados após 1970.

Aparentemente, o fenômeno do aumento de vazão decorre dos efeitos conjuntos do aumento da precipitação (que pode ser transitório), diminuição da evapotranspiração provocado pela retirada da mata nativa e aumento da infiltração da chuva, facilitada pelo adequado manejo do solo. Estes fatores podem justificar, principalmente para a área incremental, os grandes aumentos verificados nas vazões médias e vazões mínimas das bacias analisadas. A manutenção das práticas atuais de manejo integrado de bacias e incentivo aos programas de conservação do solo podem contribuir para a manutenção dos níveis atuais de vazão.

\section{REFERÊNCIAS}

BRASIL (1969). Escritório de Meteorologia. Ministério da Agricultura. Normais Climatológicas. Rio de Janeiro, v1-5, p316.

BRASIL (1992). Departamento Nacional de Meteorologia. Ministério da Agricultura e Reforma Agrária. Normais Climatológicas. Brasília, p84.

CLARKE, R. T. (1994). Statistical Modeling in Hydrology. New York: John Wiley, p412.

ELETROBRÁS (1987). Guia para cálculo de cheia de projeto de vertedores. Rio de Janeiro. p184.

GRIMM, A. (1997). Variações pluviométricas nos Estados de São Paulo e Paraná entre os períodos pré e pós 1970: possíveis causas. Curitiba. Outubro, p19. (Anexo a MÜLLER, KRÜGER e KAVISKI, 1997).

HOEL, P. G. (1984). Estatística Matemática. Rio de Janeiro: Guanabara dois, p373.

ITAIPU BINACIONAL (1995). Estudo preliminar de reavaliação do potencial hidro-energético Sumário Executivo. Área Técnica, agosto, p17.

JOHNSTON, J. (1984). Econometric Methods. New York: McGraw-Hill, p568.

LOUCKS, D. P., STEDINGER, J. R., HAITH, D. A. (1981). Water resource systems planning and 
analysis. Englewood Cliffs: Prentice Hall, p559.

MORETTIN, P. A., TOLOI, C. M. de C. (1981). Modelos para previsão de séries temporais. Rio de Janeiro: Instituto de Matemática Pura e Aplicada, v1.

MORTON, F. I. (1976). Climatological estimates of evapotranspiration. Journal of Hydrology Division, v102, n.HY3, p275-291, novembro.

ROCHA, H. O. (1997). Influência do uso da terra e dos solos sobre o aumento de vazões nas bacias hidrográficas dos rios afluentes à usina hidroelétrica de Itaipu. Curitiba. Outubro, p56. (Anexo a MÜLLER, KRÜGER e KAVISKI, 1997).

SIEGEL, S. (1956). Nonparametric statistics for the behavioral sciences. New York: McGraw-Hill, p312.

SNEDECOR, G. W., COCHRAN, W. G. Statistical methods. 6. Ed. Ames: lowa State University Press, p593.

SPIEGEL, M. R. (1978). Probabilidade e estatística. São Paulo: MacGraw-Hill, p518. (Coleção Schaum).

TUCCI, C. E. M., CLARKE, R. T. (1996a). Análise dos Estudos Hidrológicos da Reavaliação do Potencial Hidroenergético de Itaipu. Porto Alegre: IPH. Maio, p35.

TUCCI, C. E. M., CLARKE, R. T. (1996b). Impactos das mudanças ambientais nas vazões dos rios: Bacia incremental de Itaipu. Porto Alegre: IPH. Junho, p82.

\section{Stationarity Analysis of Hydrological Series in the Incremental Watershed of Itaipu}

\section{ABSTRACT}

A considerable increase in the mean flow at Itaipu was observed after 1970. This paper presents an overview of the studies developed for the analysis of time series of inflows to the Itaipu hydropower plant. The main objectives of these studies were to perform stationarity analyses of low and precipitation series and to estimate the relative variation of mean flow and mean precipitation after 1970. Several statistical techniques were employed for these analyses, with additional work being performed, in a preliminary mode, to obtain estimates of evapotranspiration and influence of meteorological aspects and land use. The studies indicated that there was a significant increase in the mean flow and mean precipitation after 1970 in the river basin considered. Apparently, the phenomenon of flow increase is caused by the joint effects of increased precipitation (which can be temporary), decrease in evapotranspiration caused by deforestation and increased infiltration due to improved soil management. The increased precipitation may justify the increased flows only upstream of the area considered. Downstream, the increase in flows is incompatible with the increase in precipitation, suggesting that other factors, such as land use change, intervene in this process. 